Research Article

\title{
Proteomic Study of HPV-Positive Head and Neck Cancers: Preliminary Results
}

\author{
Géraldine Descamps, ${ }^{1}$ Ruddy Wattiez, ${ }^{2}$ and Sven Saussez ${ }^{1}$ \\ ${ }^{1}$ Laboratory of Anatomy and Cell Biology, Faculty of Medicine and Pharmacy, University of Mons, Pentagone 2A, \\ Avenue du Champ de Mars 6, 7000 Mons, Belgium \\ ${ }^{2}$ Laboratory of Proteomics and Microbiology, Faculty of Sciences, University of Mons, Mons, Belgium \\ Correspondence should be addressed to Sven Saussez; sven.saussez@hotmail.com
}

Received 15 November 2013; Revised 20 January 2014; Accepted 23 January 2014; Published 2 March 2014

Academic Editor: Vincent Grégoire

Copyright (C) 2014 Géraldine Descamps et al. This is an open access article distributed under the Creative Commons Attribution License, which permits unrestricted use, distribution, and reproduction in any medium, provided the original work is properly cited.

\begin{abstract}
Human papillomavirus (HPV) was recently recognized as a new risk factor for head and neck squamous cell carcinoma. For oropharyngeal cancers, an HPV+ status is associated with better prognosis in a subgroup of nonsmokers and nondrinkers. However, $\mathrm{HPV}$ infection is also involved in the biology of head and neck carcinoma (HNC) in patients with a history of tobacco use and/or alcohol consumption. Thus, the involvement of HPV infection in HN carcinogenesis remains unclear, and further studies are needed to identify and analyze HPV-specific pathways that are involved in this process. Using a quantitative proteomics-based approach, we compared the protein expression profiles of two HPV+ HNC cell lines and one HPV- HNC cell line. We identified 155 proteins that are differentially expressed $(P<0.01)$ in these three lines. Among the identified proteins, prostate stem cell antigen (PSCA) was upregulated and eukaryotic elongation factor 1 alpha $(\mathrm{EEF} 1 \alpha)$ was downregulated in the HPV+ cell lines. Immunofluorescence and western blotting analyses confirmed these results. Moreover, PSCA and EEF1 $\alpha$ were differentially expressed in two clinical series of $50 \mathrm{HPV}+$ and $50 \mathrm{HPV}$ - oral cavity carcinomas. Thus, our study reveals for the first time that PSCA and EEFl $\alpha$ are associated with the HPV-status, suggesting that these proteins could be involved in HPV-associated carcinogenesis.
\end{abstract}

\section{Introduction}

Head and neck cancers (HNCs) constitute a heterogeneous group of tumors that often arise in the oral cavity, oropharynx, hypopharynx, and larynx. HNC is the sixth most common cancer, with as many as 466,831 new cases diagnosed in men in 2008 [1]. HNC generally has a poor prognosis; its 5 -year survival rate ranges between 40 and 50\%. HNC patients usually have histories of heavy tobacco and alcohol consumption. However, the International Agency for Research in Cancer (IARC) has recently recognized human papillomavirus (HPV) as a risk factor for oropharyngeal squamous cell carcinoma (OSCC). Indeed, numerous studies have provided consistent evidence that HPV has an etiologic role in 20 to $50 \%$ of OSCCs, and it is associated with a better prognosis in terms of survival and response to therapy [2].

Although the relationship between HPV infection and patient prognosis seems clear in oropharyngeal carcinoma, this relationship is less evident in the other anatomical sites affected by HNC, such as the oral cavity, larynx, and hypopharynx. The meta-analysis performed by Ragin and Taioli, which examined the relationship between HPV and overall survival, did not show any differences between HPV+ and HPV - patients with cancers at nonoropharyngeal sites [3]. Recently, we demonstrated that HPV+ oral SCC patients with a history of tobacco use and/or alcohol consumption have a significantly poorer prognosis compared to HPV- patients [4], and two Swedish studies reported that oral HPV infection is associated with a dramatically increased risk of recurrence in oral SCCs $[5,6]$. However, other studies have failed to demonstrate an association between HPV status and prognosis [7-9]. Therefore, it seems clear that the biology of oropharyngeal tumors in younger patients, nondrinkers, and nonsmokers is distinct from that of nonoropharyngeal SCC in older patients and those with a history of tobacco use and/or alcohol consumption [10]. While it is unclear whether 
TABLE 1: Description of the characteristics of the cell lines used.

\begin{tabular}{lccccc}
\hline Cell line name & Anatomical site & TNM stage & Sex & HPV status & Origin \\
\hline FaDU & Hypopharynx & T $x \mathrm{~N} x \mathrm{M} x$ & Male & HPV-negative & ATCC \\
UPCI-SCC-131 & Oral cavity & T2N2M0 & Male & HPV-negative & ATCC \\
Detroit 562 & Pharynx & TxN $x \mathrm{M} x$ & Female & HPV-negative & ATCC \\
UPCI-SCC-90 & Oropharynx & T2N1M0 & Male & HPV-positive & ATCC \\
93VU-147T & Oral cavity & T4N2 & Male & HPV-positive & University Medical \\
UPCI-SCC-154 & Oral cavity & T4N2 & Male & HPV-positive & ATCC \\
\hline
\end{tabular}

tobacco is a risk factor for HPV-induced oropharyngeal tumors, smoking has a negative impact on the survival of HPV+ patients [11]. Thus, researchers agree that there are several possible physiological states according to the patient's $\mathrm{HPV}$ infection status, which may or may not be associated with the classical risk factors. Therefore, it is important to understand these differences and the signaling pathways responsible for HPV infection.

Proteomic analysis represents a promising approach for identifying HPV-related signaling pathways. However, a paucity of literature exists regarding the biology of HPVmediated head and neck tumors. A small number of proteomic studies have been conducted, and these investigations have identified HPV-specific protein candidates in HNC. Additional proteins with altered expression levels were previously identified using $2 \mathrm{D}$ electrophoresis followed by mass spectrometry. S100A8, a calcium-binding protein, is a powerful biomarker of HPV18 infection in oral SCC patients [12] and is involved in tumor development and progression [13]. In another study, Melle et al. detected two interesting protein markers that were significantly upregulated in HPV+ oral SCC, TRX and E-FABP [14].

Here, we used a quantitative proteomic-based approach to visualize major changes in protein expression between $\mathrm{HPV}+$ and HPV - HNSCC cell lines. Among these proteins, we selected two candidates to validate our proteomic approach and studied their involvement in the carcinogenesis of $\mathrm{HPV}+$ head and neck cancers. To this end, we performed immunohistochemistry on two clinical series (50 HPV+ oral SCC patients and $50 \mathrm{HPV}$ - oral SCC patients) to support our results. In summary, this study aimed to establish a proteomic signature of HPV infection in head and neck cancer in order to better understand the mechanisms by which HPV drives head and neck carcinogenesis.

\section{Materials and Methods}

2.1. Cell Lines. The cell lines used in this study, which were derived from head and neck squamous cell carcinomas, are described in Table 1. Previous to the experiences described below, we performed PCR using E6 and E7 primers to confirm the HPV status of each cell line. The 93VU-174T cell line was obtained from Dr. de Winter (University Medical Center of Amsterdam). The UPCI-SCC-131, Detroit 562, UPCI-SCC90, and UPCI-SCC-154 cell lines were grown in Minimum Essential Medium (MEM, Gibco Life Technologies, Paisley,
UK) supplemented with $10 \%$ fetal bovine serum (FBS, Lonza, Verviers, Belgium), 2\% L-glutamine (PAA Laboratories, Pasching, Austria), 1\% penicillin/streptomycin (PAA Laboratories, Pasching, Austria), and $1 \%$ nonessential amino acids (Gibco Life Technologies, Paisley, UK) at $37^{\circ} \mathrm{C}$ in a humidified 95\% air-5\% $\mathrm{CO}_{2}$ atmosphere. The FaDU and 93VU-147T cell lines were grown in Dulbecco's Modified Eagle Medium (DMEM, Lonza, Verviers, Belgium) supplemented with $10 \%$ FBS, $2 \%$ L-glutamine, and $1 \%$ penicillin/streptomycin at $37^{\circ} \mathrm{C}$ in a humidified $95 \%$ air-5\% $\mathrm{CO}_{2}$ atmosphere. The culture medium was changed three times each week, and the cells were passaged when they reached $90 \%$ confluence. Table 1 presents the characteristics of the cell lines used in this study.

2.2. Protein Extraction and Sample Preparation. For total protein extraction, cells were washed twice in cold PBS and centrifuged, and the cell pellets were stored at $-80^{\circ} \mathrm{C}$. Protein extraction was performed using $6 \mathrm{M}$ guanidinium chloride (lysis buffer from the ICPL kit, SERVA, Germany). The solution was then ultrasonicated for $3 \times 10 \mathrm{sec}(60 \%$ amplitude, U50 IKAtechnik, IMLAB, Boutersem, Belgium) and incubated for $20 \mathrm{~min}$ at room temperature. The supernatant was recovered by centrifugation $\left(13,000 \mathrm{rpm}\right.$ for $30 \mathrm{~min}$ at $\left.4^{\circ} \mathrm{C}\right)$, and the protein concentration was determined according to the Bradford method, using bovine gamma-globulin as a standard.

The proteins were reduced, and their cysteines were alkylated using an ICPL kit (SERVA). The proteins were recovered via acetone precipitation and digested into peptides using trypsin at an enzyme/substrate ratio of 1:50 overnight at $37^{\circ} \mathrm{C}$. The next day, trypsin digestion was stopped by adding $0.1 \%$ formic acid.

2.3. Proteomic Analysis: LC MS/MS Analysis. Protein identification and quantification were performed using a labelfree strategy on an UHPLC-HRMS platform (Eksigent 2D Ultra and AB SCIEX TripleTOF 5600). The peptides $(2 \mu \mathrm{g})$ were separated on a $25 \mathrm{~cm}$ C18 column (Acclaim PepMap100, $3 \mu \mathrm{m}$, Dionex) using a linear gradient (5-35\% over $120 \mathrm{~min}$ ) of acetonitrile (ACN) in water containing $0.1 \%$ formic acid at a flow rate of $300 \mathrm{~nL} \mathrm{~min}{ }^{-1}$. To obtain the highest possible retention time stability, which is required for label-free quantification, the column was equilibrated with a $10 \times$ volume of $5 \%$ ACN before each injection. Mass spectra (MS) were acquired across $400-1500 \mathrm{~m} / \mathrm{z}$ in high-resolution mode with a $500 \mathrm{msec}$ accumulation time. The precursor selection 
parameters were as follows: intensity threshold $200 \mathrm{cps}, 50$ precursors maximum per cycle, $50 \mathrm{msec}$ accumulation time, and $15 \mathrm{sec}$ exclusion after one spectrum. These parameters led to a duty cycle of $3 \mathrm{sec}$ per cycle, ensuring that high-quality extracted ion chromatograms (XICs) were obtained for peptide quantification.

2.4. Data Processing. ProteinPilot Software (v4.1) was used to conduct a database search against the UniProt Trembl database (09/30/2011 version), which was restricted to Homo sapiens entries. The search parameters included differential amino acid mass shifts for carbamidomethyl cysteine, all biological modifications, amino acid substitutions, and missed trypsin cleavage.

For peptide quantification, PeakView was used to construct XICs for the top 5 peptides of each protein identified with an FDR lower than 1\%. Only unmodified and unshared peptides were used for quantification. Peptides were also excluded if their identification confidence was below 0.99 , as determined by ProteinPilot. A retention time window of $2 \mathrm{~min}$ and a mass tolerance of $0.015 \mathrm{~m} / \mathrm{z}$ were used. The calculated XICs were exported into MarkerView, and they were normalized based on the summed area of the entire run. Only proteins presenting a fold change higher/lower than 1.5/0.6 with a $P$ value lower than 0.05 across the 3 biological replicates analyzed were taken into account for metabolic characterization. Fold changes were assessed using Student's $t$-test. Finally, proteins identified with 1 peptide were validated manually.

2.5. Immunofluorescence Staining. Cells were seeded at a density of $5 \times 10^{5}$ cells/well in 12-well plates containing sterile round glass coverslips and grown at $37^{\circ} \mathrm{C}$ and $5 \% \mathrm{CO}_{2}$ for 5 days. The cells were washed with PBS and fixed with $4 \%$ paraformaldehyde for $15 \mathrm{~min}$. The fixed cells were rinsed with PBS, permeabilized with $0.1 \%$ Triton X-100 in PBS for $15 \mathrm{~min}$ and blocked with $0.05 \%$ casein for $20 \mathrm{~min}$. Then, the cells were treated overnight with primary antibodies against PSCA (Pierce anti-PSCA rabbit polyclonal antibody, Thermo Scientific, Rockford, USA) and EEF1 $\alpha$ (anti-EEF1A1 rabbit antibody (N-term), Abgent, Huissen, The Netherlands), which were diluted 1:50 in blocking solution. The next day, the cells were washed with PBS containing $0.1 \%$ Triton X-100 and incubated with Alexa Fluor 488-conjugated anti-rabbit IgG (Invitrogen, Gent, Belgium) for $1 \mathrm{~h}$. The cells were washed with PBS containing $0.1 \%$ Triton X-100 for $15 \mathrm{~min}$, rinsed with distilled water for $10 \mathrm{~min}$ and mounted with Vectashield Mounting Medium containing DAPI (Vector Laboratories). The cells were observed by confocal microscopy using an Olympus FV1000D laser scanning inverted microscope (Olympus, Hamburg, Germany). The exposure time of each photo was $27.59 \mathrm{~s} /$ frame, pictures were captured at $1600 \mathrm{pix} / 1600 \mathrm{pix}$, and the pixel time was $10.0 \mu \mathrm{s} / \mathrm{pix}$. The background noise was adjusted in the same manner and to the same level for each picture. Each picture was analyzed semiquantitatively.

2.6. Western Blot Analysis. Proteins were extracted from cells using BugBuster Protein extraction reagent (Novagen,
Darmstadt, Germany), and the protein concentrations of the extracts were determined using a Bio-Rad protein assay (BioRad Laboratories, München, Germany). Four microliters $4 \times$ LDS sample buffer (NuPAGE, Invitrogen) and $1 \mu \mathrm{L} 20 \times$ reducing agent (Fermentas) were added to each protein extract, and the sample volume was brought to $20 \mu \mathrm{L}$ with deionized water. The samples were heated at $95^{\circ} \mathrm{C}$ for $5 \mathrm{~min}$, and $30 \mu \mathrm{g}$ of proteins was separated on $4-20 \%$ Mini Protean Gels (BioRad Laboratories, München, Germany). After electrophoresis, the proteins were electrotransferred onto nitrocellulose membranes (Hybond ECL, Amersham). Nonspecific binding sites were blocked by incubation with PBS containing 5\% nonfat milk at room temperature for $1 \mathrm{~h}$. Immunodetection was performed overnight at $4^{\circ} \mathrm{C}$ using antiEEF1 $\alpha$ (anti-EEF1A1 rabbit antibody (N-term), Abgent, Huissen, The Netherlands) and anti-PSCA (Pierce anti-PSCA rabbit polyclonal antibody, Thermo Scientific, Rockford, USA) antibodies, which were diluted 1:100 in PBS containing 2\% nonfat milk. The membrane was washed three times with PBS and incubated for $1 \mathrm{~h}$ at room temperature with HRP-conjugated goat anti-rabbit IgG (GE Healthcare Life Sciences, Buckinghamshire, UK), which was diluted in PBS containing $2 \%$ nonfat milk. The bound peroxidase was detected using the SuperSignal West Femto kit (Roche), and the bands were visualized by exposing the membranes to photosensitive film (Hyperfilm ECL, Amersham Pharmacia Biotech).

2.7. Patients and Tissue Samples. We examined 100 formalinfixed, paraffin-embedded oral SCC specimens obtained from patients who underwent radical curative surgery between January 2004 and December 2008 at Saint Pieter's Hospital (Brussels) or the EpiCURA Center (Baudour). The tumors were classified according to the TNM classification of the International Union Against Cancer. Table 2 presents the clinical data of our patients. Among these 100 cases, 50 were $\mathrm{HPV}+$ and 50 were HPV-. This study was approved by the Saint Pieter's Hospital Institutional Review Board (AK/0909-47/3805AD).

2.8. HPV Detection and Typing. HPV detection and typing of paraffin-embedded tissues were performed as described in our previous work [9]. DNA extraction was performed using a QIAamp DNA Mini Kit (Qiagen, Benelux, Belgium), according to the manufacturer's protocol. HPV was detected using PCR with GP5+/GP6+ primers. All DNA extracts were analyzed for the presence of 18 different HPV genotypes using a TaqMan-based real-time quantitative PCR targeting typespecific sequences of the following viral genes: $6 \mathrm{E} 6,11 \mathrm{E} 6,16$ E7, 18 E7, 31 E6, 33 E6, 35 E6, 39 E7, 45 E7, 51 E6, 52 E7, 53 E6, 56 E7, 58 E6, 59 E7, 66 E6, 67 L1, and 68 E7. In each PCR assay, $\beta$ globin levels were assessed using real-time quantitative PCR to verify the quality of the DNA in the samples and measure the amount of input DNA.

2.9. Immunohistochemistry of HPV+ and HPV-Oral Carcinoma Samples. All tumors samples were fixed for $24 \mathrm{~h}$ in $10 \%$ buffered formaldehyde, dehydrated, and embedded in paraffin. Immunohistochemistry was performed on $5 \mu \mathrm{m}$ thick 
TABLE 2: Clinical data of the 100 oral SCC patients.

\begin{tabular}{|c|c|}
\hline Variables & Number of cases \\
\hline \multicolumn{2}{|l|}{ Age (years) } \\
\hline Range & $36-90$ \\
\hline Mean & 58 \\
\hline \multicolumn{2}{|l|}{ Sex } \\
\hline Male & 82 \\
\hline Female & 18 \\
\hline \multicolumn{2}{|l|}{ Anatomic site } \\
\hline Cheeks & 4 \\
\hline Mouth floor & 32 \\
\hline Tongue & 36 \\
\hline Gums & 8 \\
\hline Mandible & 5 \\
\hline Palate & 2 \\
\hline Retromolar trigone & 2 \\
\hline Lips & 2 \\
\hline Other & 9 \\
\hline \multicolumn{2}{|l|}{ Grade (differentiation) } \\
\hline Well & 30 \\
\hline Moderately & 51 \\
\hline Poorly & 19 \\
\hline \multicolumn{2}{|l|}{ TNM stage } \\
\hline $\mathrm{T} 1-\mathrm{T} 2$ & 72 \\
\hline T3-T4 & 28 \\
\hline \multicolumn{2}{|l|}{$\mathrm{N}$ stage } \\
\hline No & 53 \\
\hline N1 & 12 \\
\hline $\mathrm{N} 2$ & 33 \\
\hline N3 & 2 \\
\hline \multicolumn{2}{|l|}{ Metastasis } \\
\hline M0 & 100 \\
\hline M1 & 0 \\
\hline \multicolumn{2}{|l|}{ Risk factors } \\
\hline \multicolumn{2}{|l|}{ Tobacco (90 cases) } \\
\hline Smoker & 67 \\
\hline Nonsmoker & 16 \\
\hline Former smoker & 7 \\
\hline \multicolumn{2}{|l|}{ Alcohol (90 cases) } \\
\hline Drinker & 58 \\
\hline Nondrinker & 9 \\
\hline Former drinker & 23 \\
\hline \multicolumn{2}{|l|}{ Histology } \\
\hline Bone infiltration & 2 \\
\hline Perineural invasion & 10 \\
\hline Positive node & 19 \\
\hline Capsular evasion & 11 \\
\hline \multicolumn{2}{|l|}{ Recurrence } \\
\hline Local & 11 \\
\hline Ganglionic & 6 \\
\hline Distant metastases & 4 \\
\hline
\end{tabular}

sections mounted on silane-coated glass sides. The paraffinembedded tissue specimens were deparaffinized in toluene, soaked in ethanol, and then soaked in PBS. They were pretreated in a pressure cooker (11 min for PSCA and 6 min for $\mathrm{EEF} 1 \alpha$ ) in a $10 \%$ citrate buffer solution (for EEF1 $\alpha$ ) or a $10 \%$ EDTA solution (for PSCA) to unmask the antigens. Then, the sections were incubated in $0.06 \%$ hydrogen peroxide for 5 min to block endogenous peroxidase activity, rinsed in PBS, blocked with Protein Block (Serum-Free, Dako, Carpinteria, USA), and incubated at $4^{\circ} \mathrm{C}$ overnight with rabbit anti-PSCA (Thermo Scientific, Rockford, USA) or anti-EEF1 $\alpha$ (BioConnect, TE Huissen, The Netherlands). The next day, the tissues were incubated with Post Blocking Antibody for $15 \mathrm{~min}$, followed by PowerVision (ImmunoLogic, Duiven, The Netherlands) for $30 \mathrm{~min}$. The slides were washed with PBS between incubation steps. Finally, the localization of the antibody/antigen complex was visualized by staining with DAB (BioGenex, Fremont, USA), and the sections were counterstained with Luxol Fast Blue and mounted with a synthetic medium. To exclude antigen-independent staining, controls, for which the incubation step with the primary antibody was omitted, were examined. In all cases, these controls were negative.

2.10. Semiquantitative Immunohistochemical Analysis. Two independent investigators, who were blinded to the clinical details of the patients, assessed PSCA and EEFl $\alpha$ immunoreactivities in all tumor areas using an optical microscope (Axiocam MRc5, Zeiss). The mean intensity (MI) was defined as follows: 0 (negative), 1 (weak), 2 (moderate), and 3 (strong). The percentage of immunopositive cells (labeling index, LI) was categorized as follows: 0 ( $0 \%$ positive cells), 1 (1-25\%), $2(26-75 \%)$, and $3(76-100 \%)$. Statistical analysis was performed using the Mann-Whitney test to compare the MI and LI values between the HPV+ and HPV- samples.

\section{Results}

3.1. Protein Profiling of HPV+ versus HPV- Head and Neck Cancer Cell Lines. Protein profiling using label-free quantification was conducted to identify proteins whose expression was altered by HPV infection. To elucidate the specific effects of HPV in head and neck carcinogenesis and identify potential candidates, we compared the differential patterns of protein expression between one HPV - cell line ( $\mathrm{FaDU})$ and two HPV+ cell lines (93VU-147T and UPCI-SCC90). Proteins extracts were analyzed in triplicate for each cell line using tandem mass spectrometry.

For this analysis, we were interested in proteins that had increased or decreased expression levels and are clinically relevant.

Analysis of the three cancer cell lines identified 2221 proteins, among which 155 were differentially expressed between the HPV- and HPV+ cells with significant $P$ values of $<0.01$; 56 of these were downregulated, and 99 were upregulated (Table 3 ). Two interesting candidates caught our attention due to their known properties and their large fold changes. The expression of prostate stem cell antigen (PSCA) 
TABLE 3: Proteins with decreased and increased abundance between the HPV-cell line and the HPV+ cell lines.

\begin{tabular}{|c|c|c|c|c|}
\hline Accession number & $P$ value & Fold change & Protein name & $\begin{array}{c}\text { Number of peptide } \\
\text { identified (95\%) }\end{array}$ \\
\hline tr|D3DWI6|D3DWI6_HUMAN & 0.007 & 0.007 & Prostate stem cell antigen & 1 \\
\hline $\operatorname{tr}|\mathrm{Q} 6 \mathrm{LES} 2| \mathrm{Q} 6 \mathrm{LES2}$ _HUMAN & 0.000005 & 0.045 & ANXA4 protein & 22 \\
\hline $\operatorname{tr|B3KY42|B3KY42\_ HUMAN~}$ & 0.001 & 0.062 & $\begin{array}{l}\text { cDNA FLJ46788 fis, clone TRACH3028855, } \\
\text { highly similar to Pseudouridylate synthase } 7\end{array}$ & 1 \\
\hline $\operatorname{tr}|\mathrm{B} 4 \mathrm{E} 2 \mathrm{Q} 6| \mathrm{B} 4 \mathrm{E} 2 \mathrm{Q} 6 \_H U M A N$ & 0.003 & 0.093 & $\begin{array}{l}\text { Regulation of nuclear pre-mRNA } \\
\text { domain-containing protein } 2\end{array}$ & 2 \\
\hline tr|F8WE04|F8WE04_HUMAN & 0.00156 & 0.111 & Heat shock protein beta-1 & 54 \\
\hline 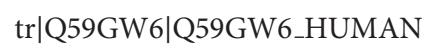 & 0.00375 & 0.134 & Acetyl-CoA acetyltransferase, cytosolic variant & 20 \\
\hline 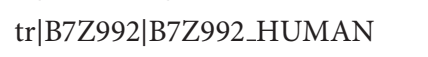 & 0.00369 & 0.137 & cDNA FLJ53698, highly similar to Gelsolin & 39 \\
\hline 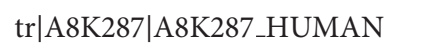 & 0.00793 & 0.143 & Synaptosomal-associated protein & 1 \\
\hline 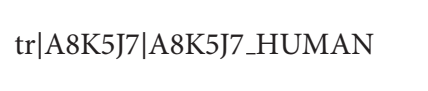 & 0.00757 & 0.150 & $\begin{array}{l}\text { cDNA FLJ77290, highly similar to Homo sapiens } \\
\text { BCL2-associated athanogene } 5\end{array}$ & 1 \\
\hline 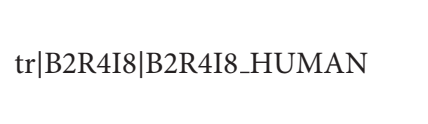 & 0.00098 & 0.159 & $\begin{array}{l}\text { cDNA, FLJ92106, highly similar to Homo sapiens } \\
\text { adaptor-related protein complex } 3 \text {, sigma } 1 \\
\text { subunit(AP3S1), }\end{array}$ & 2 \\
\hline tr|E9PPU0|E9PPU0_HUMAN & 0.00505 & 0.168 & Epiplakin & 97 \\
\hline tr|B7Z6B8|B7Z6B8_HUMAN & 0.00178 & 0.171 & 2,4-dienoyl-CoA reductase, mitochondrial & 10 \\
\hline 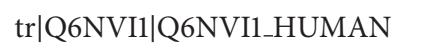 & 0.00008 & 0.197 & MARCKS protein & 26 \\
\hline 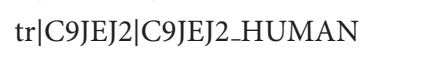 & 0.00782 & 0.199 & Choline-phosphate cytidylyltransferase A & 15 \\
\hline tr|Q9BRV4|Q9BRV4_HUMAN & 0.00187 & 0.202 & $\begin{array}{l}\text { Vesicle-associated membrane protein } 3 \\
\text { (Cellubrevin) }\end{array}$ & 3 \\
\hline 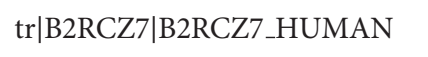 & 0.00005 & 0.204 & Ethylmalonic encephalopathy 1, isoform CRA_a & 18 \\
\hline $\operatorname{tr|B4DL87|B4DL87\_ HUMAN~}$ & 0.00444 & 0.206 & $\begin{array}{l}\text { cDNA FLJ52243, highly similar to Heat-shock } \\
\text { protein beta-1 }\end{array}$ & 70 \\
\hline 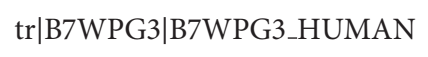 & 0.00444 & 0.208 & Heterogeneous nuclear ribonucleoprotein L-like & 1 \\
\hline 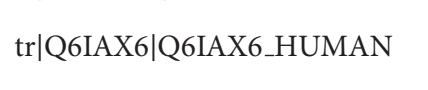 & 0.00052 & 0.213 & $\begin{array}{l}3^{\prime} \text {-phosphoadenosine } 5^{\prime} \text {-phosphosulfate synthase } \\
1 \text { OS }\end{array}$ & 1 \\
\hline tr|E7EMB1|E7EMB1_HUMAN & 0.00413 & 0.227 & Switch-associated protein 70 & 9 \\
\hline 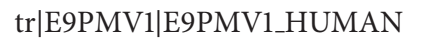 & 0.00202 & 0.238 & Plectin & 10 \\
\hline tr|F5GXF7|F5GXF7_HUMAN & 0.00479 & 0.252 & Zinc finger protein 185 & 16 \\
\hline 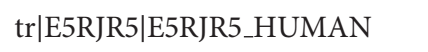 & 0.00022 & 0.252 & S-phase kinase-associated protein 1 & 4 \\
\hline 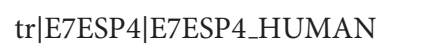 & 0.00135 & 0.259 & Integrin alpha-2 & 12 \\
\hline 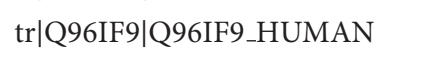 & 0.00454 & 0.273 & VCP protein & 112 \\
\hline 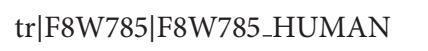 & 0.00221 & 0.276 & Golgi integral membrane protein 4 & 1 \\
\hline tr|B7Z5V6|B7Z5V6_HUMAN & 0.00881 & 0.278 & $\begin{array}{l}\text { cDNA FLJ57046, highly similar to Lysosomal } \\
\text { alpha-glucosidase }\end{array}$ & 4 \\
\hline $\operatorname{tr|A6NEL0|A6NEL0\_ HUMAN~}$ & 0.00582 & 0.279 & Non-histone chromosomal protein HMG-14 & 19 \\
\hline tr|G0TQY6|G0TQY6_HUMAN & 0.00471 & 0.281 & Lutheran blood group & 19 \\
\hline $\operatorname{tr}|\mathrm{A} 8 \mathrm{~K} 4 \mathrm{~W} 6| \mathrm{A} 8 \mathrm{~K} 4 \mathrm{~W} 6 \_\mathrm{HUMAN}$ & 0.00045 & 0.287 & Phosphoglycerate kinase & 123 \\
\hline 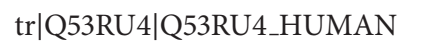 & 0.00154 & 0.292 & Putative uncharacterized protein $\mathrm{MSH} 2$ & 4 \\
\hline $\operatorname{tr}|\mathrm{A} 8 \mathrm{~K} 2 \mathrm{Y} 9| \mathrm{A} 8 \mathrm{~K} 2 \mathrm{Y9}$ 9_HUMAN & 0.0011 & 0.308 & $\begin{array}{l}\text { 6-phosphogluconate dehydrogenase, } \\
\text { decarboxylating }\end{array}$ & 33 \\
\hline 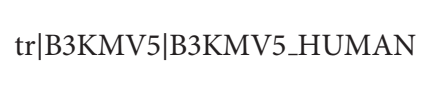 & 0.00078 & 0.319 & $\begin{array}{l}\text { cDNA FLJ12728 fis, clone NT2RP2000040, highly } \\
\text { similar to Protein FAM62A }\end{array}$ & 9 \\
\hline $\operatorname{tr|B3KMN7|B3KMN7/HUMAN~}$ & 0.00131 & 0.320 & cDNA FLJ11717 fis, clone HEMBA1005241 & 5 \\
\hline $\operatorname{tr|B4DN60|B4DN60\_ HUMAN~}$ & 0.00015 & 0.323 & Asparagine-tRNA ligase, cytoplasmic & 10 \\
\hline $\operatorname{tr|B1ANK7|B1ANK7/HUMAN~}$ & 0.00465 & 0.347 & Fumarate hydratase & 19 \\
\hline
\end{tabular}


TABle 3: Continued.

\begin{tabular}{|c|c|c|c|c|}
\hline Accession number & $P$ value & Fold change & Protein name & $\begin{array}{c}\text { Number of peptide } \\
\text { identified }(95 \%)\end{array}$ \\
\hline tr|Q0VDC6|Q0VDC6_HUMAN & 0.00257 & 0.357 & FKBP1A protein & 9 \\
\hline $\operatorname{tr} \mid$ C8KIL8|C8KIL8_HUMAN & 0.00769 & 0.368 & $\begin{array}{l}\text { Glutathione reductase delta8 alternative splicing } \\
\text { variant }\end{array}$ & 1 \\
\hline 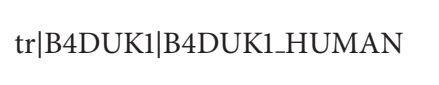 & 0.00161 & 0.375 & $\begin{array}{l}\text { cDNA FLJ51310, moderately similar to } \\
\text { Peroxiredoxin-6 }\end{array}$ & 10 \\
\hline 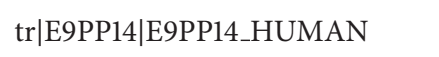 & 0.00564 & 0.383 & GDP-L-fucose synthase & 1 \\
\hline tr|D6RE99|D6RE99_HUMAN & 0.00776 & 0.399 & Histidine triad nucleotide-binding protein 1 & 8 \\
\hline tr|B1AKP7|B1AKP7_HUMAN & 0.00099 & 0.403 & TAR DNA binding protein & 11 \\
\hline tr|Q6FHQ6|Q6FHQ6_HUMAN & 0.00442 & 0.418 & IDH1 protein & 21 \\
\hline 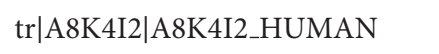 & 0.00771 & 0.421 & Histone $1, \mathrm{H} 1 \mathrm{c}$ & 123 \\
\hline $\operatorname{tr} \mid$ A0PK02|A0PK02_HUMAN & 0.00526 & 0.424 & PLXNB2 protein & 3 \\
\hline 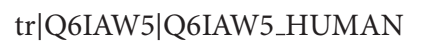 & 0.00939 & 0.446 & CALU protein & 22 \\
\hline 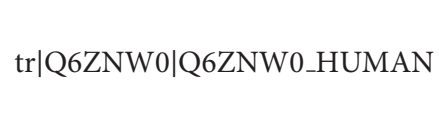 & 0.0098 & 0.449 & $\begin{array}{l}\text { cDNA FLJ } 27036 \text { fis, clone SLV08019, highly } \\
\text { similar to Homo sapiens stomatin (EPB72)-like } 2 \\
\text { (STOML2) }\end{array}$ & 10 \\
\hline $\operatorname{tr}|\mathrm{A} 4 \mathrm{UCS} 8| \mathrm{A} 4 \mathrm{UCS} 8 \_\mathrm{HUMAN}$ & 0.00267 & 0.455 & Enolase & 130 \\
\hline 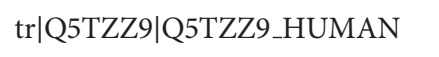 & 0.00184 & 0.461 & ANXA1 protein & 96 \\
\hline 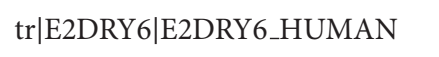 & 0.00118 & 0.504 & Enolase & 217 \\
\hline 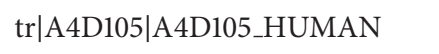 & 0.00122 & 0.514 & Replication protein $\mathrm{A} 3,14 \mathrm{kDa}$ & 7 \\
\hline $\operatorname{tr}|\mathrm{Q} 5 \mathrm{TCI} 8| \mathrm{Q} 5 \mathrm{TCI} 8$ HUMAN & 0.00168 & 0.530 & Lamin A/C & 119 \\
\hline 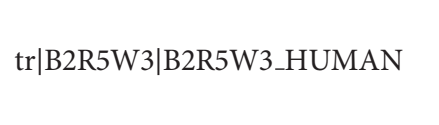 & 0.00065 & 0.566 & $\begin{array}{l}\text { cDNA, FLJ92658, highly similar to Homo sapiens } \\
\text { poly (ADP-ribose) polymerase family, member } 1 \\
\text { (PARP1) }\end{array}$ & 51 \\
\hline 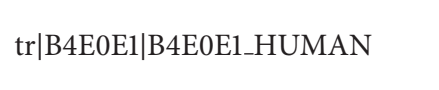 & 0.00065 & 0.566 & $\begin{array}{l}\text { cDNA FLJ53442, highly similar to Poly } \\
\text { (ADP-ribose) polymerase } 1\end{array}$ & 52 \\
\hline $\operatorname{tr|D6W5C0|D6W5C0\_ HUMAN~}$ & 0.0096 & 0.608 & Spectrin, beta, nonerythrocytic 1 , isoform CRA_b & 39 \\
\hline tr|E9KL44|E9KL44_HUMAN & 0.00912 & 0.646 & Epididymis tissue sperm binding protein & 39 \\
\hline 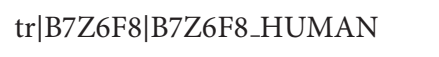 & 0.00713 & 1.244 & Clathrin interactor 1 & 6 \\
\hline $\operatorname{tr}|\mathrm{A} 8 \mathrm{~K} 7 \mathrm{~A} 4| \mathrm{A} 8 \mathrm{~K} 7 \mathrm{~A} 4 \_\mathrm{HUMAN}$ & 0.00524 & 1.414 & $\begin{array}{l}\text { cDNA FLJ76904, highly similar to Homo sapiens } \\
\text { methionine adenosyltransferase II, beta (MAT2B) }\end{array}$ & 12 \\
\hline 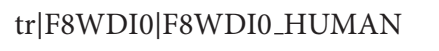 & 0.00874 & 1.505 & Ubiquitin-like-conjugating enzyme ATG3 & 2 \\
\hline $\operatorname{tr|B3KRT1|B3KRT1\_ HUMAN~}$ & 0.00437 & 1.706 & Inositol-3-phosphate synthase 1 & 11 \\
\hline 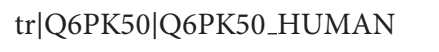 & 0.0069 & 1.788 & HSP90AB1 protein & 65 \\
\hline $\operatorname{tr}|\mathrm{Q} 6 \mathrm{NVC0}| \mathrm{Q} 6 \mathrm{NVC0}$ _HUMAN & 0.00315 & 1.80 & SLC25A5 protein & 37 \\
\hline tr|E5RH41|E5RH41_HUMAN & 0.00169 & 1.848 & Transcription initiation factor IIE subunit beta & 1 \\
\hline 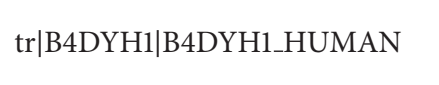 & 0.00023 & 1.878 & $\begin{array}{l}\text { Heat shock } 105 \mathrm{kDa} / 110 \mathrm{kDa} \text { protein 1, isoform } \\
\text { CRA_b }\end{array}$ & 52 \\
\hline tr|E9PQI8|E9PQI8_HUMAN & 0.00195 & 1.888 & U4/U6.U5 tri-snRNP-associated protein 1 & 3 \\
\hline tr|B5BTY7|B5BTY7_HUMAN & 0.00798 & 1.966 & T-complex protein 1 subunit beta & 46 \\
\hline 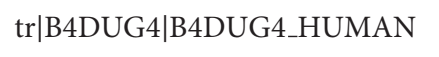 & 0.00275 & 1.975 & cDNA FLJ51308 & 1 \\
\hline tr|B3KTJ9|B3KTJ9_HUMAN & 0.00804 & 1.975 & cDNA FLJ38393 fis, clone FEBRA2007212 & 15 \\
\hline 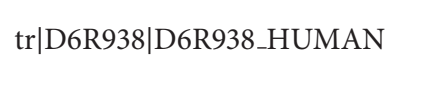 & 0.00024 & 1.986 & $\begin{array}{l}\text { Calcium/calmodulin-dependent protein kinase } \\
\text { (CaM kinase) II delta }\end{array}$ & 2 \\
\hline $\operatorname{tr} \mid$ A8K259|A8K259_HUMAN & 0.00046 & 2.070 & $\begin{array}{l}\text { cDNA FLJ78501, highly similar to Homo sapiens } \\
\text { serpin peptidase inhibitor, clade H (heat shock } \\
\text { protein } 47 \text { ), member 1, (collagen binding protein } \\
\text { 1) (SERPINH1) }\end{array}$ & 18 \\
\hline 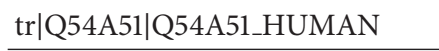 & 0.00291 & 2.079 & Basigin (Ok blood group), isoform CRA_a & 20 \\
\hline
\end{tabular}


TABle 3: Continued.

\begin{tabular}{|c|c|c|c|c|}
\hline Accession number & $P$ value & Fold change & Protein name & $\begin{array}{l}\text { Number of peptide } \\
\text { identified }(95 \%)\end{array}$ \\
\hline tr|Q6IPH7|Q6IPH7_HUMAN & 0.00287 & 2.131 & RPL14 protein & 19 \\
\hline tr|A8K9U6|A8K9U6_HUMAN & 0.00504 & 2.132 & $\begin{array}{l}\text { cDNA FLJ76121, highly similar to Homo sapiens } \\
\text { zinc finger CCCH-type, antiviral } 1 \text { (ZC3HAV1) }\end{array}$ & 7 \\
\hline 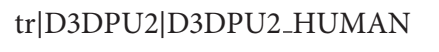 & 0.00049 & 2.135 & Adenylyl cyclase-associated protein & 59 \\
\hline $\operatorname{tr|B3KN49|B3KN49\_ HUMAN~}$ & 0.00667 & 2.165 & $\begin{array}{l}\text { cDNA FLJ13562 fis, clone PLACE1008080, highly } \\
\text { similar to Homo sapiens hexamethylene } \\
\text { bis-acetamide inducible } 1 \text { (HEXIM1) }\end{array}$ & 6 \\
\hline 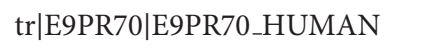 & 0.0005 & 2.167 & Serpin H1 & 17 \\
\hline 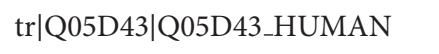 & 0.00597 & 2.195 & YBX1 protein & 25 \\
\hline tr|E7EQV9|E7EQV9_HUMAN & 0.00711 & 2.247 & Ribosomal protein L15 & 5 \\
\hline $\operatorname{tr} \mid$ A8K2Q6|A8K2Q6_HUMAN & 0.00501 & 2.278 & Peptidyl-prolyl cis-trans isomerase & 3 \\
\hline 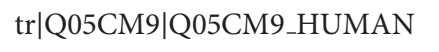 & 0.000005 & 2.287 & PSIP1 protein & 18 \\
\hline tr|Q7L7Q6|Q7L7Q6_HUMAN & 0.00109 & 2.321 & RTN4 & 6 \\
\hline tr|Q5U077|Q5U077_HUMAN & 0.00247 & 2.379 & L-lactate dehydrogenase & 38 \\
\hline $\operatorname{tr} \mid$ F5GZA8|F5GZA8_HUMAN & 0.00582 & 2.384 & SH3 domain-binding protein 1 & 6 \\
\hline tr|E7EPK6|E7EPK6_HUMAN & 0.00396 & 2.394 & 40 S ribosomal protein $\mathrm{S} 24$ & 7 \\
\hline $\operatorname{tr}|\mathrm{Q} 8 \mathrm{TBR} 3| \mathrm{Q} 8 \mathrm{TBR} 3$ HUMAN & 0.00685 & 2.414 & $\begin{array}{l}\text { Fusion (Involved in } \mathrm{t}(12 ; 16) \text { in malignant } \\
\text { liposarcoma) }\end{array}$ & 33 \\
\hline tr|A8MX94|A8MX94_HUMAN & 0.00964 & 2.475 & Glutathione S-transferase P & 50 \\
\hline 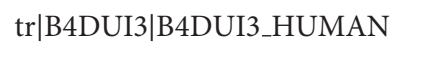 & 0.00619 & 2.484 & Eukaryotic translation initiation factor 3 subunit $J$ & 10 \\
\hline 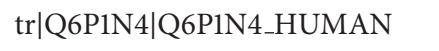 & 0.00019 & 2.492 & IQGAP1 protein & 64 \\
\hline $\operatorname{tr}|\mathrm{A} 4 \mathrm{QPB} 0| \mathrm{A} 4 \mathrm{QPB} 0 \_\mathrm{HUMAN}$ & 0.00019 & 2.492 & IQ motif containing GTPase activating protein 1 & 83 \\
\hline 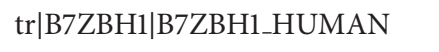 & 0.00876 & 2.499 & Eukaryotic translation initiation factor 6 & 9 \\
\hline 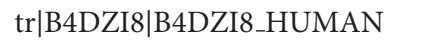 & 0.00931 & 2.525 & Coatomer protein complex, subunit beta 2 & 8 \\
\hline $\operatorname{tr} \mid$ B4DWA0|B4DWA0_HUMAN & 0.00454 & 2.535 & $\begin{array}{l}\text { cDNA FLJ54188, moderately similar to High } \\
\text { mobility group protein HMG-I/HMG-Y }\end{array}$ & 8 \\
\hline 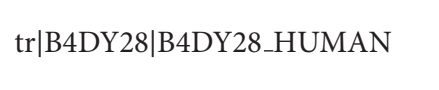 & 0.0063 & 2.556 & $\begin{array}{l}\text { cDNA FLJ61189, highly similar to Cysteine and } \\
\text { glycine-rich protein } 1\end{array}$ & 2 \\
\hline tr|B7Z921|B7Z921_HUMAN & 0.00179 & 2.601 & $\begin{array}{l}\text { cDNA FLJ61669, highly similar to Transcription } \\
\text { elongation regulator } 1\end{array}$ & 5 \\
\hline 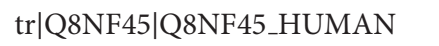 & 0.00368 & 2.657 & FLJ00353 protein & 8 \\
\hline 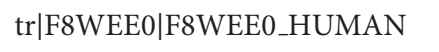 & 0.00313 & 2.672 & Protein NDRG1 & 1 \\
\hline tr|E9PIM9|E9PIM9_HUMAN & 0.00026 & 2.676 & Ribonuclease H1 & 24 \\
\hline 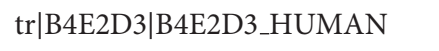 & 0.00154 & 2.685 & Nuclear pore complex protein Nup50 & 4 \\
\hline 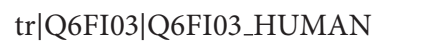 & 0.00472 & 2.715 & G3BP protein & 27 \\
\hline 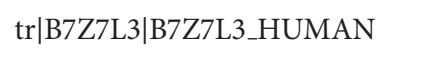 & 0.00077 & 2.752 & NADH-cytochrome b5 reductase 3 & 10 \\
\hline $\operatorname{tr|B1AH89|B1AH89\_ HUMAN~}$ & 0.00436 & 2.775 & Tubulin tyrosine ligase-like family, member 12 & 14 \\
\hline 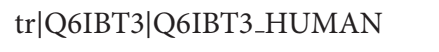 & 0.00347 & 2.783 & CCT7 protein & 37 \\
\hline 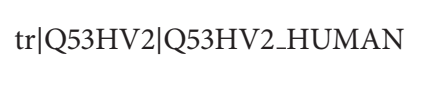 & 0.00347 & 2.783 & $\begin{array}{l}\text { Chaperonin containing TCP1, subunit } 7 \text { (Eta) } \\
\text { variant }\end{array}$ & 45 \\
\hline 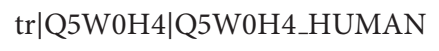 & 0.00403 & 2.793 & Tumor protein, translationally controlled 1 & 13 \\
\hline 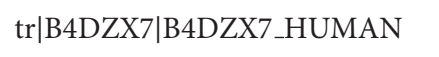 & 0.00318 & 2.817 & Thioredoxin domain containing, isoform CRA_b & 1 \\
\hline $\operatorname{tr|B3KRA1|B3KRA1\_ HUMAN~}$ & 0.00016 & 2.844 & $\begin{array}{l}\text { cDNA FLJ33914 fis, clone CTONG2016575, highly } \\
\text { similar to SON PROTEIN }\end{array}$ & 3 \\
\hline 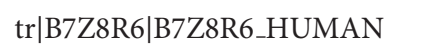 & 0.00049 & 2.846 & cDNA FLJ51445, highly similar to AMBP protein & 1 \\
\hline 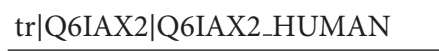 & 0.0057 & 2.852 & RPL21 protein & 13 \\
\hline
\end{tabular}


TABle 3: Continued.

\begin{tabular}{|c|c|c|c|c|}
\hline Accession number & $P$ value & Fold change & Protein name & $\begin{array}{l}\text { Number of peptide } \\
\text { identified }(95 \%)\end{array}$ \\
\hline $\operatorname{tr}|\mathrm{B} 2 \mathrm{R} 4 \mathrm{~F} 3| \mathrm{B} 2 \mathrm{R} 4 \mathrm{~F} 3$ HUMAN & 0.00842 & 2.868 & $\begin{array}{l}\text { cDNA, FLJ92068, highly similar to Homo sapiens } \\
\text { Rho GDP dissociation inhibitor (GDI) beta } \\
\text { (ARHGDIB) }\end{array}$ & 3 \\
\hline 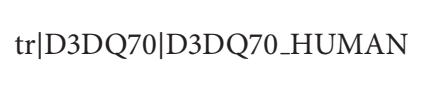 & 0.00312 & 2.882 & $\begin{array}{l}\text { SERPINE1 mRNA binding protein 1, isoform } \\
\text { CRA_d }\end{array}$ & 15 \\
\hline 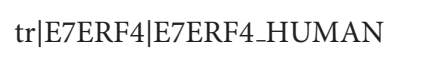 & 0.00326 & 2.973 & Adenylosuccinate lyase & 10 \\
\hline 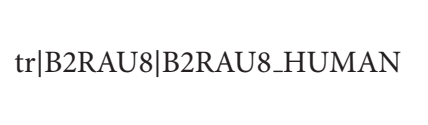 & 0.00573 & 3.071 & $\begin{array}{l}\text { cDNA, FLJ95131, highly similar to Homo sapiens } \\
\text { nucleolar and coiled-body phosphoprotein } 1 \\
\text { (NOLC1) }\end{array}$ & 11 \\
\hline tr|B4DIT0|B4DIT0_HUMAN & 0.00069 & 3.098 & Anion exchange protein 2 & 2 \\
\hline 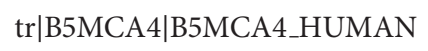 & 0.00511 & 3.111 & Epithelial cell adhesion molecule & 4 \\
\hline 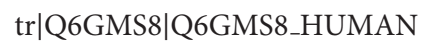 & 0.00075 & 3.140 & Syntaxin-16 & 2 \\
\hline 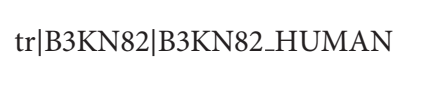 & 0.00899 & 3.209 & $\begin{array}{l}\text { cDNA FLJ13913 fis, clone Y79AA1000231, highly } \\
\text { similar to Nucleolar protein NOP5 }\end{array}$ & 12 \\
\hline $\operatorname{tr|B4E0L0|B4E0L0\_ HUMAN~}$ & 0.00362 & 3.211 & $\begin{array}{l}\text { cDNA FLJ54030, highly similar to Polymerase } \\
\text { delta-interacting protein } 3\end{array}$ & 9 \\
\hline 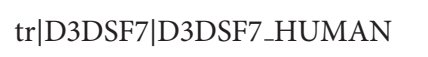 & 0.00302 & 3.236 & SON DNA binding protein, isoform CRA_b & 7 \\
\hline 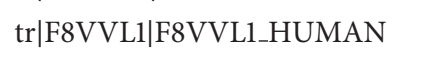 & 0.00199 & 3.278 & Density-regulated protein & 6 \\
\hline $\operatorname{tr} \mid$ A8K787|A8K787_HUMAN & 0.0069 & 3.285 & $\begin{array}{l}\text { cDNA FLJ75273, highly similar to Homo sapiens } \\
\text { solute carrier family } 25 \text { (mitochondrial carrier; } \\
\text { adenine nucleotide translocator), member } 4\end{array}$ & 17 \\
\hline 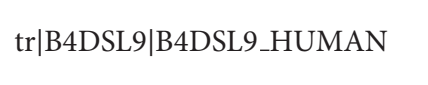 & 0.00403 & 3.297 & $\begin{array}{l}\text { cDNA FLJ58748, highly similar to U3 small } \\
\text { nucleolar RNA-associated protein 6homolog }\end{array}$ & 2 \\
\hline 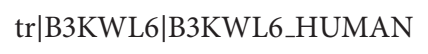 & 0.00036 & 3.382 & Methionine aminopeptidase & 7 \\
\hline 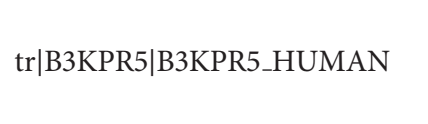 & 0.00165 & 3.421 & $\begin{array}{l}\text { cDNA FLJ32094 fis, clone OCBBF2000986, highly } \\
\text { similar to Homo sapiens elongation factor Tu GTP } \\
\text { binding domain containing } 1 \text {, transcript variant } 1\end{array}$ & 1 \\
\hline 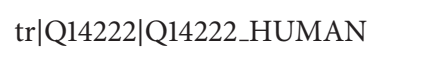 & 0.00673 & 3.562 & EEF1A protein & 108 \\
\hline tr|Q16577|Q16577_HUMAN & 0.00673 & 3.562 & Elongation factor 1-alpha & 143 \\
\hline 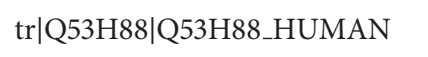 & 0.0034 & 3.579 & Dynactin 2 variant & 7 \\
\hline tr|Q59GP5|Q59GP5_HUMAN & 0.00198 & 3.601 & $\begin{array}{l}\text { Eukaryotic translation elongation factor } 1 \text { alpha } 2 \\
\text { variant }\end{array}$ & 45 \\
\hline $\operatorname{tr|Q68CS0|Q68CS0\_ HUMAN~}$ & 0.00079 & 3.630 & Ornithine aminotransferase, mitochondrial & 7 \\
\hline tr|F5GXR3|F5GXR3_HUMAN & 0.00387 & 3.972 & Parathymosin & 1 \\
\hline $\operatorname{tr} \mid$ F5H8L6|F5H8L6_HUMAN & 0.00141 & 3.996 & Dipeptidyl peptidase 3 & 17 \\
\hline tr|Q6IPS9|Q6IPS9_HUMAN & 0.00459 & 4.001 & Elongation factor 1-alpha & 311 \\
\hline tr|F8W940|F8W940_HUMAN & 0.00537 & 4.120 & CUGBP Elav-like family member 1 & 3 \\
\hline 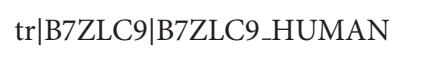 & 0.00416 & 4.234 & GEMIN5 protein & 3 \\
\hline 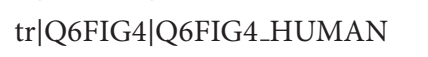 & 0.00017 & 4.372 & RAB1B protein & 19 \\
\hline 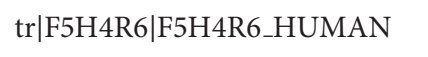 & 0.00067 & 4.373 & Nucleosome assembly protein 1-like 1 & 32 \\
\hline 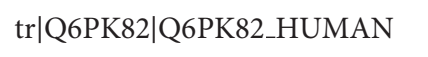 & 0.00008 & 4.425 & AP3D1 protein & 5 \\
\hline $\operatorname{tr|B3KW52|B3KW52\_ HUMAN~}$ & 0.0073 & 4.443 & $\begin{array}{l}\text { cDNA FLJ42145 fis, clone TESTI4000228, highly } \\
\text { similar to Mus musculus ubiquitin family domain } \\
\text { containing } 1 \text { (Ubfd1), mRNA }\end{array}$ & 2 \\
\hline tr|E9PS95|E9PS95_HUMAN & 0.00885 & 4.636 & Mitochondrial glutamate carrier 1 & 1 \\
\hline tr|Q6FH57|Q6FH57_HUMAN & 0.00045 & 4.653 & Peptidyl-prolyl cis-trans isomerase & 4 \\
\hline 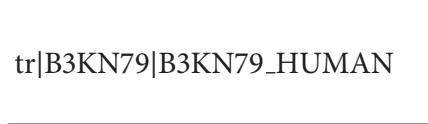 & 0.00107 & 4.681 & $\begin{array}{l}\text { cDNA FLJ13894 fis, clone THYRO1001671, highly } \\
\text { similar to } 59 \mathrm{kDa} 2^{\prime}-5^{\prime} \text {-oligoadenylate } \\
\text { synthetase-like protein }\end{array}$ & 3 \\
\hline
\end{tabular}


TABLe 3: Continued.

\begin{tabular}{|c|c|c|c|c|}
\hline Accession number & $P$ value & Fold change & Protein name & $\begin{array}{c}\text { Number of peptide } \\
\text { identified }(95 \%)\end{array}$ \\
\hline 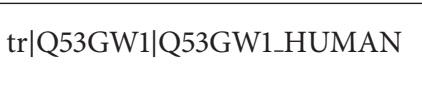 & 0.00487 & 4.697 & $\begin{array}{l}\text { Vesicle transport-related protein isoform a variant } \\
\text { (Fragment) }\end{array}$ & (1) \\
\hline tr|Q5U0I6|Q5U0I6_HUMAN & 0.00098 & 4.810 & RAB1A protein & 14 \\
\hline 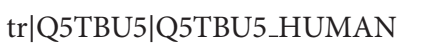 & 0.00439 & 5.144 & Adipose specific 2 & 1 \\
\hline tr|E9PK25|E9PK25_HUMAN & 0.000007 & 6.239 & Cofilin-1 & 96 \\
\hline tr|F8W7I9|F8W7I9_HUMAN & 0.00003 & 6.928 & Ran GTPase-activating protein 1 & 15 \\
\hline $\operatorname{tr|B3KU10|B3KU10\_ HUMAN~}$ & 0.00049 & 7.509 & Interferon-induced GTP-binding protein $\mathrm{Mxl}$ & 22 \\
\hline tr|Q75MY7|Q75MY7_HUMAN & 0.0005 & 7.948 & $\mathrm{MX} 2$ & 11 \\
\hline tr|D2KFR9|D2KFR9_HUMAN & 0.00057 & 8.090 & $\begin{array}{l}\text { Signal transducer and activator of transcription } \\
\text { 1-alpha/beta }\end{array}$ & 3 \\
\hline tr|E9PCQ3|E9PCQ3_HUMAN & 0.00031 & 8.511 & Ubiquitin carboxyl-terminal hydrolase & 1 \\
\hline tr|B4DTE6|B4DTE6_HUMAN & 0.0066 & 8.644 & $\begin{array}{l}\text { cDNA FLJ56243, highly similar to } \\
\text { Melanoma-associated antigen } 4\end{array}$ & 6 \\
\hline 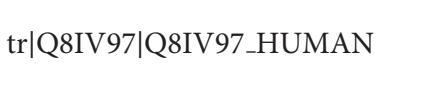 & 0.00356 & 10.882 & $\begin{array}{l}\text { Solute carrier family } 7 \text { (Cationic amino acid } \\
\text { transporter, y+ system), member } 5\end{array}$ & 3 \\
\hline tr|Q96J85|Q96J85_HUMAN & 0.00055 & 14.133 & $\mathrm{C}-\mathrm{Mpl}$ binding protein & 1 \\
\hline tr|F5H667|F5H667_HUMAN & 0.00003 & 16.263 & Aspartyl/asparaginyl beta-hydroxylase & 4 \\
\hline $\operatorname{tr} \mid$ A5GZA6|A5GZA6_HUMAN & 0.000002 & 53.611 & Cysteine-rich with EGF-like domain protein 2 & 2 \\
\hline 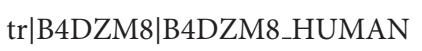 & 0.00002 & 145.941 & $26 \mathrm{~S}$ proteasome non-ATPase regulatory subunit 5 & 2 \\
\hline
\end{tabular}

(Accession number: D3DWI6) was reduced 140-fold in the FaDu cells compared to the HPV+ cell lines. Moreover, PSCA has been reported to be oncogenic in some epithelial cells and a tumor suppressor in others. Eukaryotic elongation factor 1 $\alpha$ (EEF1 $\alpha)$ (Accession number: Q6IPS9) expression was four fold higher in the HPV- cells than the HPV+ cell lines. Its upregulation was recently reported to be associated with increased cell proliferation and oncogenic transformation.

3.2. PSCA and EEFla Expression in Different HPV+ and HPV- Head and Neck Cancer Cell Lines. To confirm our mass spectrometry results, we studied the expression of PSCA and EEF $1 \alpha$ by immunocytochemistry in six head and neck cancer cell lines: $3 \mathrm{HPV}+$ cell lines (93VU-147T, UPCI-SCC90 and UPCI-SCC154) and 3 HPV- cell lines (FaDU, Detroit and UPCI-SCC131). The results of the immunofluorescence analysis of PSCA in all cell lines are presented in Figure 1. PSCA was mainly nuclear, but it was also distributed at a low level throughout the cytoplasm. PSCA was overexpressed in HPV + cell lines compared to HPV - cell lines (Figures 1(a), $1(b)$, and $1(c))$. These results are consistent with those obtained in our proteomic analysis.

Figure 2 illustrates the differential expression of EEF1 $\alpha$ between HPV+ and HPV- cell lines. EEFl $\alpha$ was primarily nuclear, but it was also diffuse throughout the cytoplasm. We also noted a marked difference in the expression of this protein in both cell populations (HPV+ and HPV-). In fact, as expected, confocal microscopy examination of EEF1 $\alpha$ revealed an increase in the intensity of the immunofluorescence signal in the HPV - cells (Figures 2(d), 2(e), and 2(f)) compared to the HPV+ cells, which showed weak expression of
EEF1 $\alpha$ (Figures 2(a), 2(b), and 2(c)). This observation was validated using western blotting to compare the EEF1 $\alpha$ expression levels of the cell lines used in our proteomic analysis. In FaDU cell extracts, a band was detected at $50 \mathrm{kDa}$, which corresponds to the mass of the EEFl $\alpha$ protein (Figure 3). This band was not observed in the HPV+ cell lines. We used actin as a loading control, which was detected at $43 \mathrm{kDa}$ in the extracts from all three cell lines (Figure 3). After several attempts, we were not able to validate PSCA expression by western blotting because the primary antibody was not suitable for this technique.

3.3. PSCA Protein Expression in Surgical Specimens of OSCC. Among the $50 \mathrm{HPV}+$ cases, qRT-PCR targeting $18 \mathrm{HPV}$ subtypes revealed that $100 \%$ of the cases were infected by HPV16, with two coinfections, HPV-53 and HPV-39. After confirming our results in vitro, we evaluated PSCA expression in clinical series of oral cancer. Fifty HPV+ and fifty HPV- oral cancer specimens were examined by immunohistochemistry. As shown in Figure 4(d), PSCA immunostaining was strong in both the cytoplasm and nucleus (Figure $4(\mathrm{~d})$ ). To determine whether there was differential protein expression, we compared the two groups (HPV+ versus HPV-) using a nonparametric Mann-Whitney test (Figure 4(e)). PSCA was significantly upregulated in the HPV+ oral tumors compared to the HPV- oral tumors $(P=0.006)$ in terms of the labeling index (LI), which corresponds to the percentage of immunopositive cells.

3.4. EEF1 $\alpha$ Protein Expression in Surgical Specimens of OSCC. Figures 5(c) and 5(d) present the results of our immunohistochemical analysis of EEF1 $\alpha$ expression in the same 


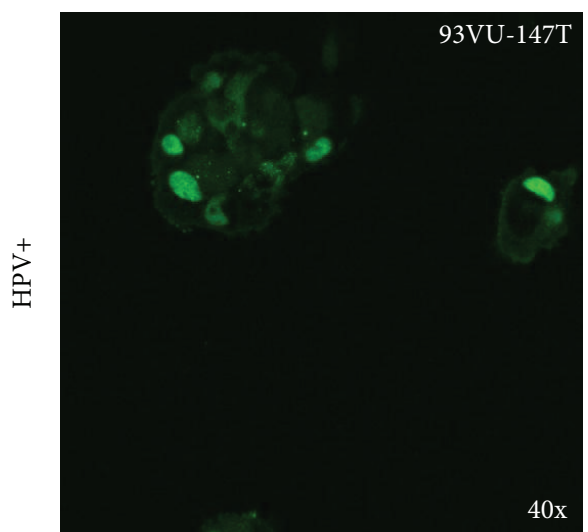

(a)

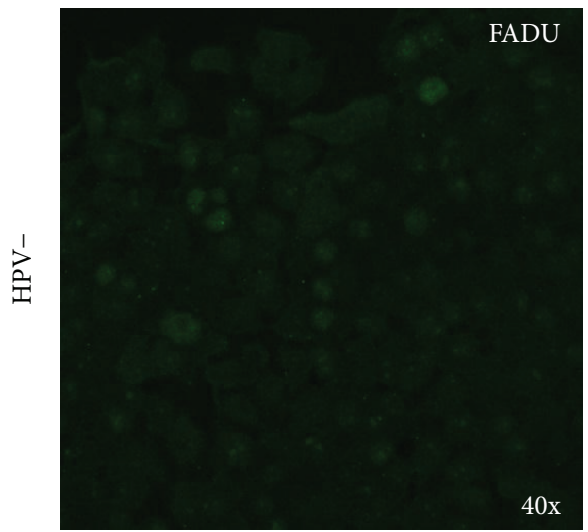

(d)

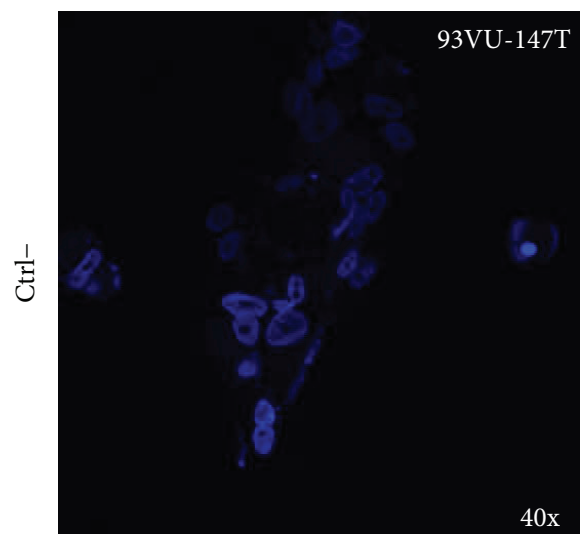

(g)

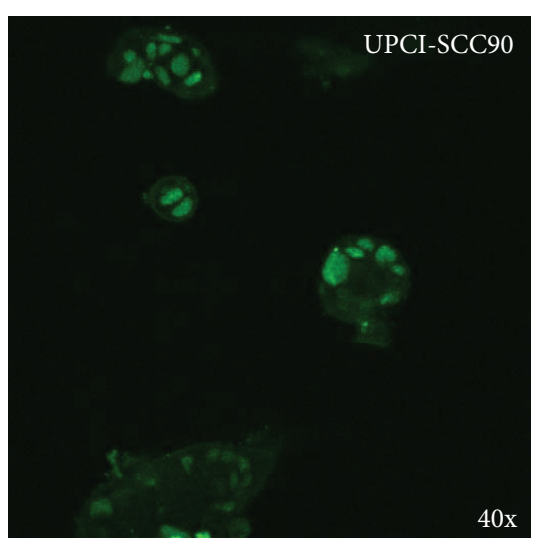

(b)

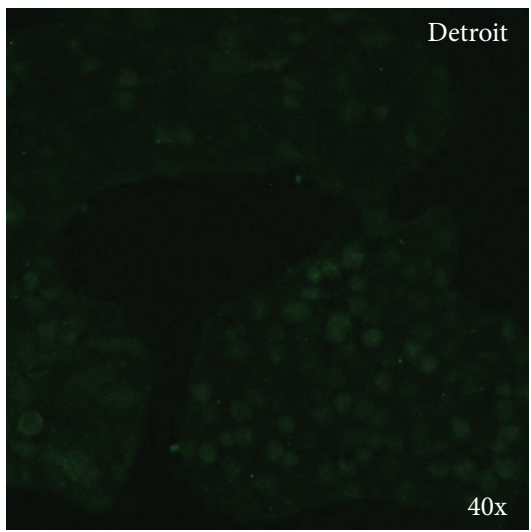

(e)

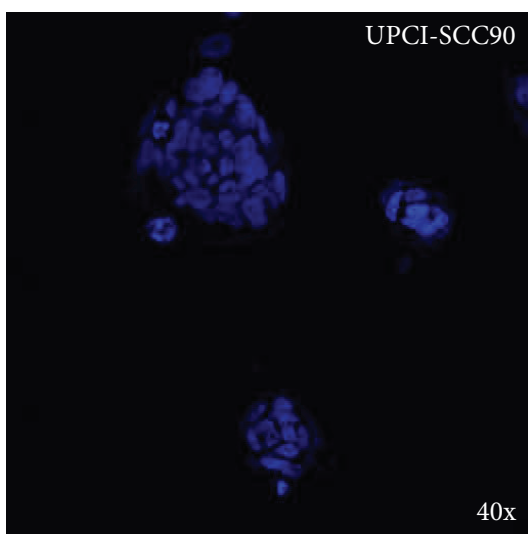

(h)

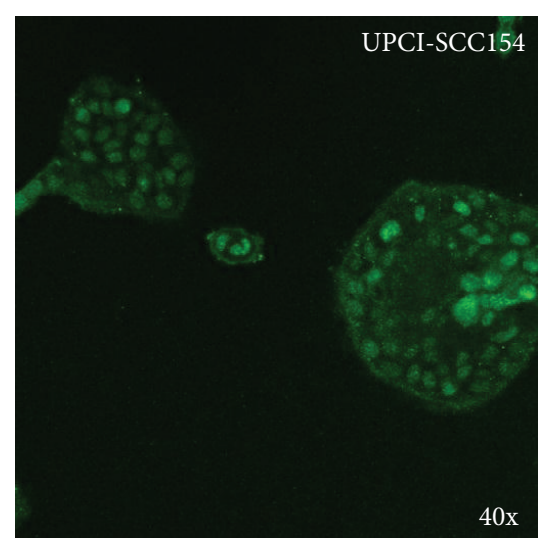

(c)

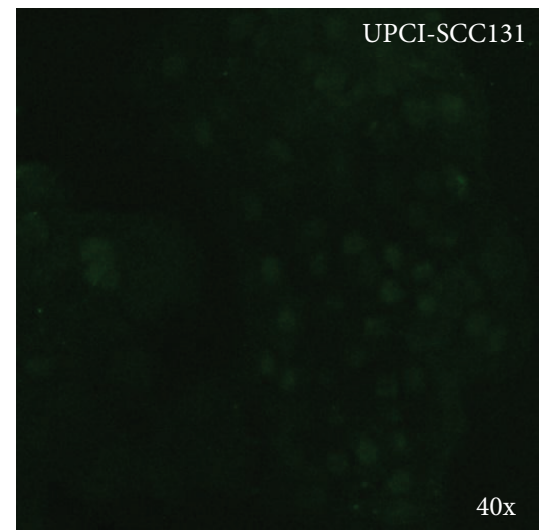

(f)

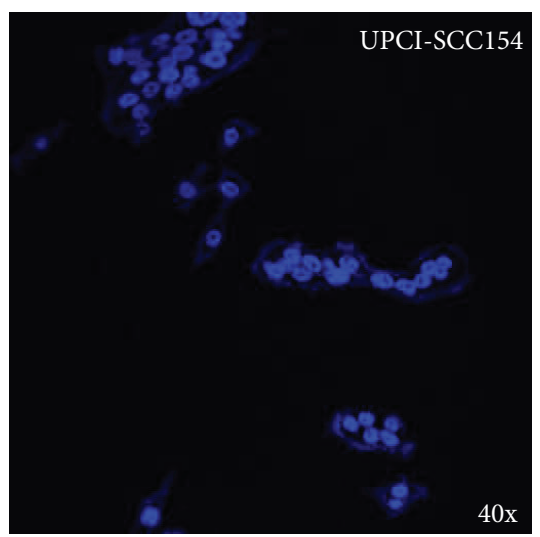

(i)

Figure 1: Immunofluorescence staining of PSCA in three HPV+ cell lines ((a), (b), and (c)) and three HPV- cell lines with control DAPI staining ((d), (e), and (f)). Alexa Fluor 488 labeling; confocal microscopy; exposure time of 27.59 s/frame; capture condition of $1600 \mathrm{pix} / 1600$ pix and pixel time of $10.0 \mu \mathrm{s} / \mathrm{pix}$.

clinical series (50 HPV+ OSCCs versus $50 \mathrm{HPV}$ - OSCCs). EEF1 $\alpha$ was localized in both the nucleus and cytoplasm, but significantly stronger staining intensity was observed in the nucleus (Figure 5(d)). As expected, semiquantitative analysis demonstrated that EEF1 $\alpha$ expression was increased in $\mathrm{HPV}$ - carcinomas compared to HPV+ carcinomas. Indeed, a statistically significant difference in terms of the mean intensity (MI) values between the $\mathrm{HPV}+$ and $\mathrm{HPV}-$ tumors was calculated using a nonparametric Mann-Whitney test $(P=0.03)$ (Figure 5(e)).

\section{Discussion}

Recent advances have been made in our understanding of the relationship between head and neck carcinogenesis and HPV. Strong evidence indicates that HPV+ HNSCC 


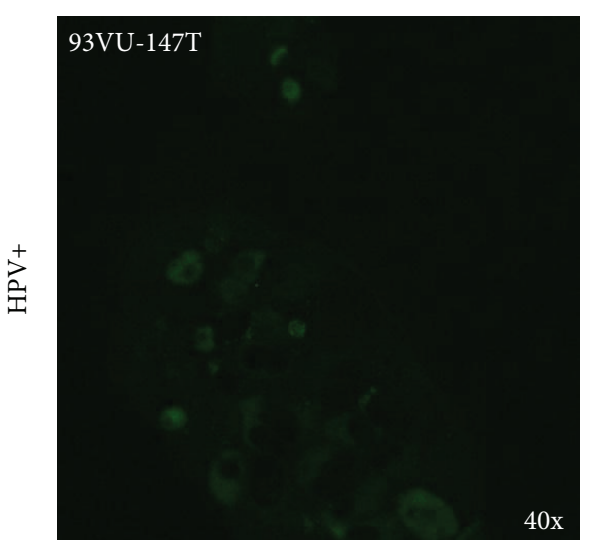

(a)

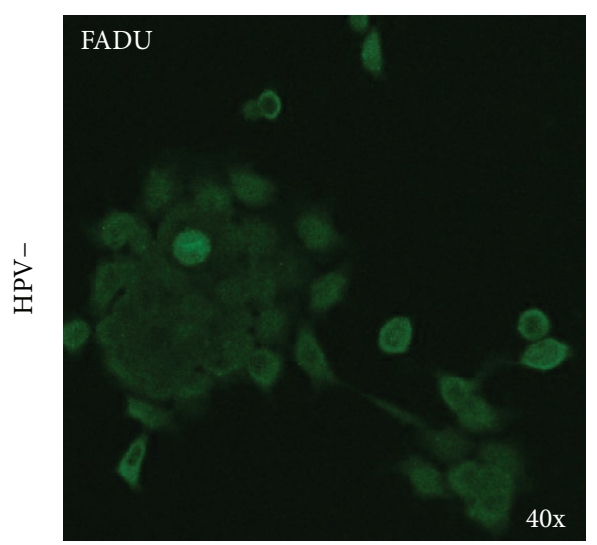

(d)

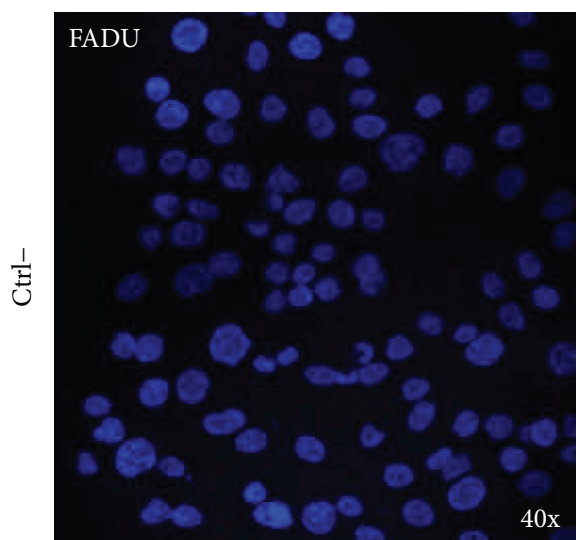

(g)

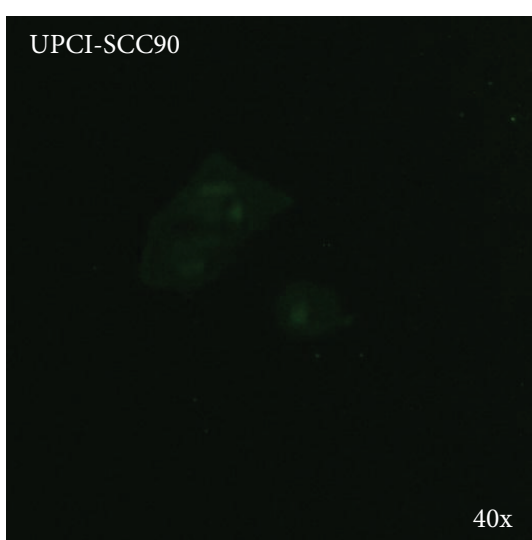

(b)

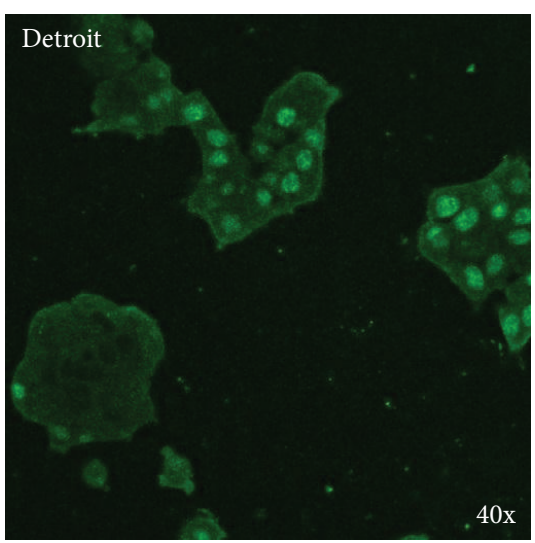

(e)

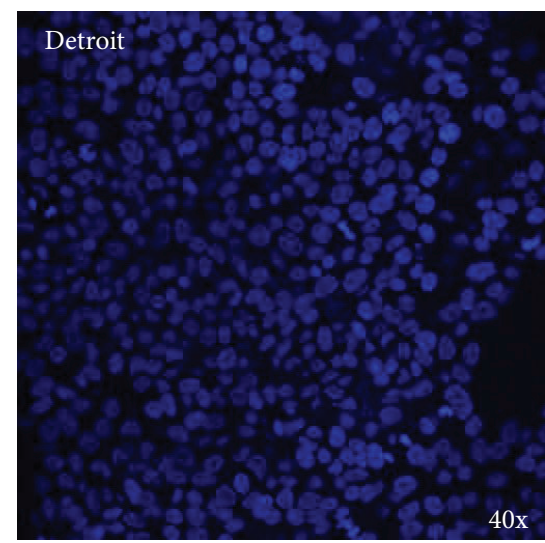

(h)

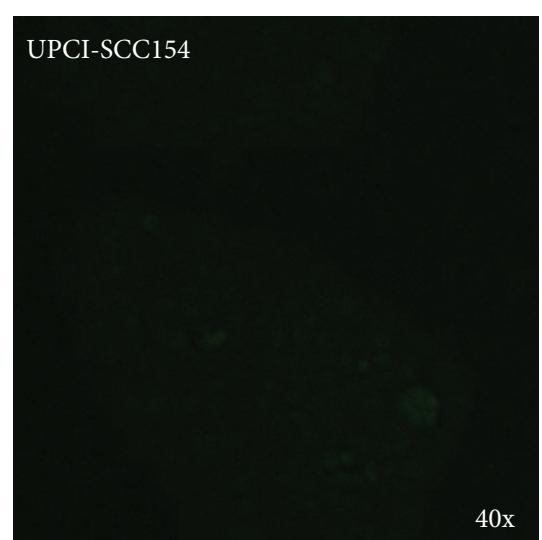

(c)

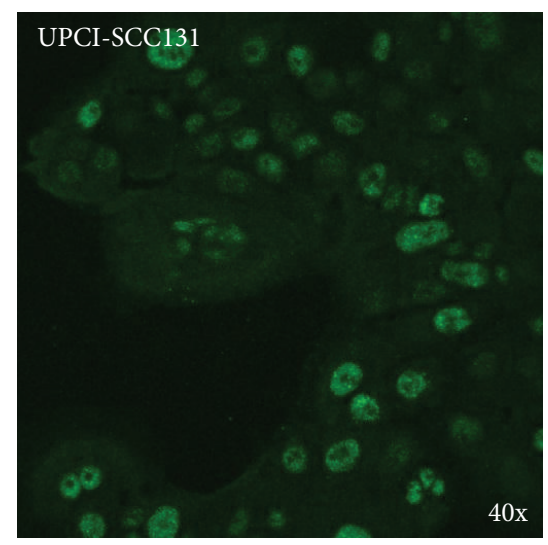

(f)

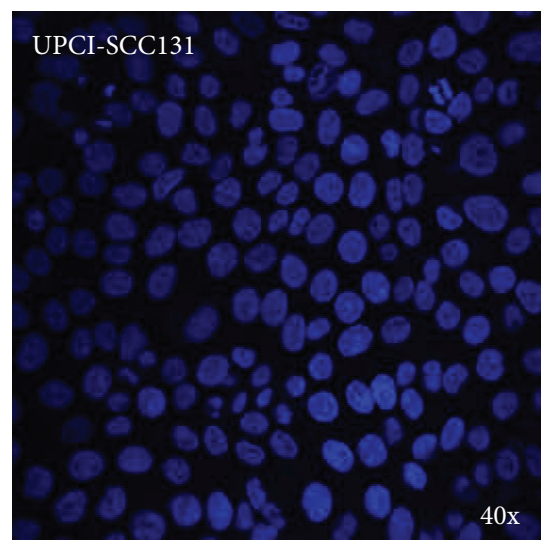

(i)

Figure 2: Immunofluorescence staining of EEF1 $\alpha$ in three HPV+ cell lines with control DAPI staining ((a), (b), and (c)) and three HPV- cell lines ((d), (e), and (f)). Alexa Fluor 488 labeling; confocal microscopy; exposure time of 27.59 s/frame; capture condition of 1600 pix/1600 pix and pixel time of $10.0 \mu \mathrm{s} /$ pix.

comprise a subclass of tumors with a different biology and different clinical properties and that affects specific demographic pop-ulations. HPV+ tumors occur in a younger age group, originate more frequently in the oropharynx, and have a lower T stage compared to HPV- tumors [15]. At the histopathological level, we distinguished distinct features of $\mathrm{HPV}+$ tumors, including their identification as nonkeratinizing basal cells and their prominent "koilocytic" morphology
[16]. Concerning overall survival, the majority of studies agree that HPV-infected patients have a better prognosis. $\mathrm{HPV}+$ and HPV - tumors also exhibit differences in tumor biology, with HPV+ tumors having fewer p53 mutations and displaying reduced association with tobacco and alcohol consumption $[17,18]$. These observations suggest that HPV+ HNSCC and HPV- HNSCC should be considered two distinct cancers with distinct biological pathways: one driven 


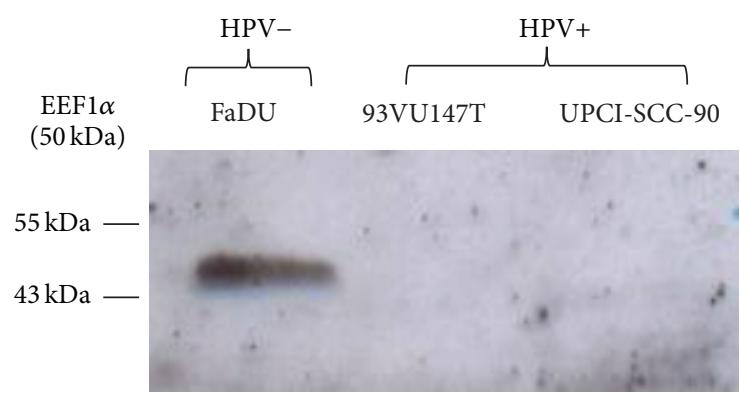

(a)

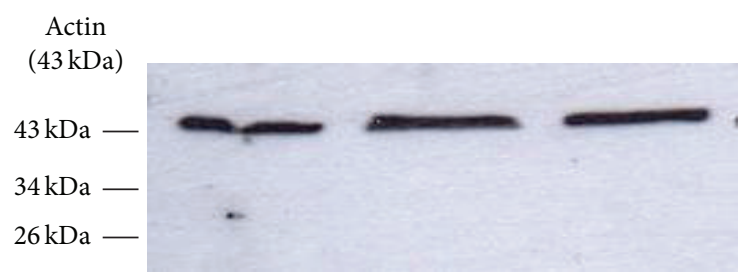

(b)

FIGURE 3: Western blot analysis demonstrating the upregulation of EEF1 $\alpha$ in the HPV- cell line, FaDu.

by environmental agents (tobacco and alcohol) and the other driven by infectious agents (high-risk HPV subtypes). However, these two pathologic agents may interact and act synergistically to promote the development of HNSCC.

Despite the progress made in the field of HPV-related HNSCC, a paucity of literature exists with respect to studies investigating the biology of HPV infection in head and neck carcinogenesis. Disease predictors are important from both the clinical and molecular perspectives. Current HNSCC treatments are frequently associated with adverse side effects, and $50 \%$ of HNSCC patients die within two years of their initial diagnosis because two-thirds of patients have advanced cancer (stage III or IV) at diagnosis [19, 20]. Therefore, novel approaches are needed to aid clinicians by providing them relevant predictive candidates for the disease to improve patient management. Beyond the clinical challenges, understanding the molecular mechanisms underlying this disease is crucial for developing targeted therapies and individualizing treatment based on the biology of the tumor. In this context, we investigated the global protein expression of three head and neck cancer cell lines, two HPV+ and one HPV-. First, we compared the two populations to identify differences in their proteomic patterns and, consequently, potential candidates of HPV infection. Second, we validated the selected proteins using a clinical series of 100 oral SCC samples (50 $\mathrm{HPV}+$ and $50 \mathrm{HPV}-$ ).

Over the past decade, technological advances have been made in the field of proteomics, leading to the identification of specific proteins that are differentially expressed in tumor and control specimens. Mass spectrometry is undoubtedly the most powerful technology for proteomics. The most current mass spectrometers present high resolving power and mass accuracy, allowing for the detection and quantification of thousands of proteins. Thus, clinical proteomics is a powerful diagnostic and prognostic technology. However, advances in the proteomics field have resulted in publications describing numerous potential cancer markers that must be clinically validated prior to the development of a diagnostic test.

In our study, we used liquid chromatography coupled to electrospray ionization tandem mass spectrometry to analyze tryptic peptides from three cell lines (2 HPV+ and $1 \mathrm{HPV}-$ ). This technology allowed us to identify and quantify 2221 proteins, among which 155 were differentially expressed between the HPV - and HPV+ cells with significant $P$ values of $<0.01$. The strength of our study lies in the clinical validation of our potential candidates. Indeed, there is a limitation in using cultured cells rather than clinical specimens, as the proteomes of cells grown in vitro may not accurately reflect those of in vivo cancer cells. However, if the selected protein candidates are further investigated by immunohistochemistry (IHC) using patient tissue samples, the proteomic analysis of cultured cells is entirely valid for the identification of putative candidates. Ye et al. identified 40 differentially expressed proteins between three paired oral SCC cell lines with different metastatic potentials. They were able to confirm their results by IHC and, consequently, identified superoxide dismutase 2 (SOD2) as a predictive marker for the diagnosis of metastasis [21].

Similarly, we validated several of the differentially expressed proteins between the HPV- and HPV+ populations in our study using three different methods. Immunocytochemistry and western blotting confirmed our mass spectrometry results, and IHC also demonstrated those statistically significant differences in $50 \mathrm{HPV}+$ and $50 \mathrm{HPV}-$ oral SCC specimens. In fact, HPV+ oral carcinoma s overexpressed prostate stem cell antigen (PSCA) compared to HPV - oral carcinomas. PSCA was discovered fifteen years ago. It is a glycosylphosphatidylinositol (GPI)-anchored cell surface protein belonging to the Thy-1/Ly-6 family [22]. PSCA was initially identified in prostate cancer but is also expressed in epithelial cells of various organs, such as the bladder, kidney, skin, esophagus, stomach, placenta, and lung [23-26]. Little is known about its physiological functions and signaling cascade, but recently, it was defined as a "Jekyll and Hyde" molecule due to its expression pattern. PSCA seems to act as an oncogene in some cancers, such as prostate, bladder, renal and ovarian carcinomas, and as a tumor suppressor in others, including esophageal and gastric cancer [27]. To date, only one study reported decreased PSCA expression (100fold) in HNSCC [25].

PSCA seems to be involved in cell growth regulation and to play some roles in signal transduction. Other members of the Ly- 6 superfamily are involved in cell adhesion, cell migration, and the regulation of T lymphocyte regulation [28-30]. PSCA overexpression in prostate cancer is related to c-myc amplification [24]. In addition, siRNA-mediated knockdown of PSCA significantly reduces lung cancer cell growth [26]. The same observation was recently made in human prostate cancer cells [31]. Moreover, PSCA is downregulated in gallbladder, esophagus, and stomach tumors $[23,32]$, as well as our HPV- HNC cell line (FaDU). Therefore, it would be interesting to further validate and explore the clinical implications of PSCA. 


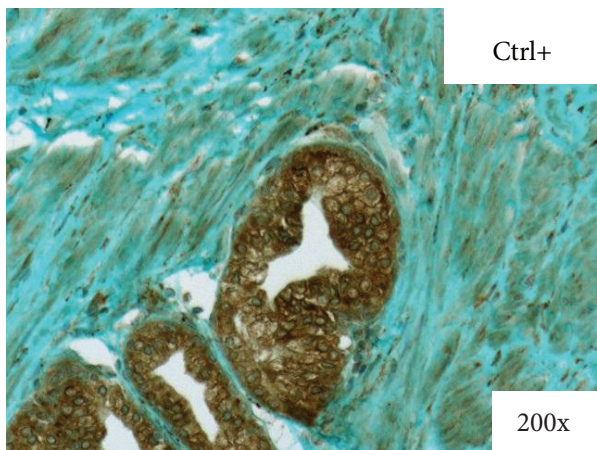

(a)

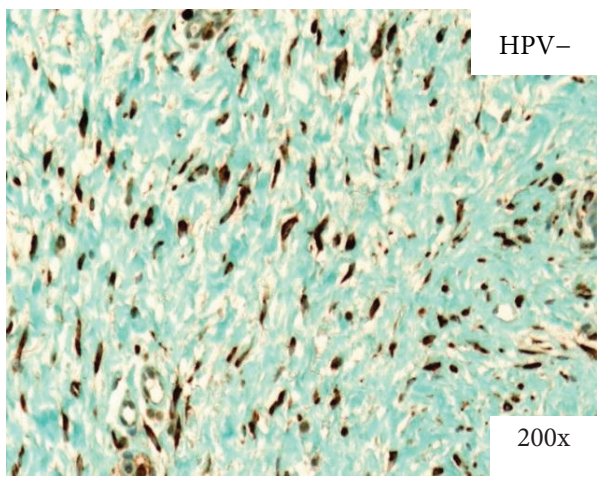

(c)

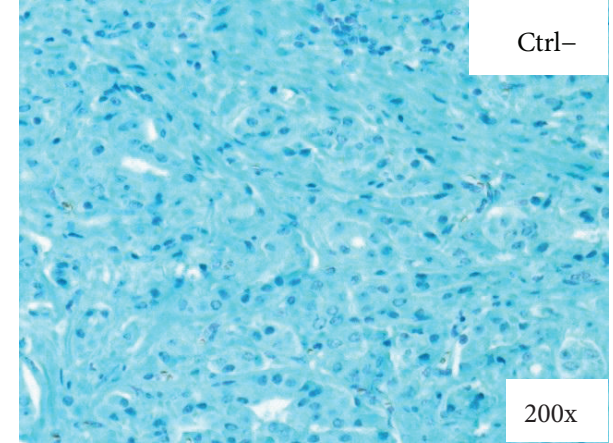

(b)

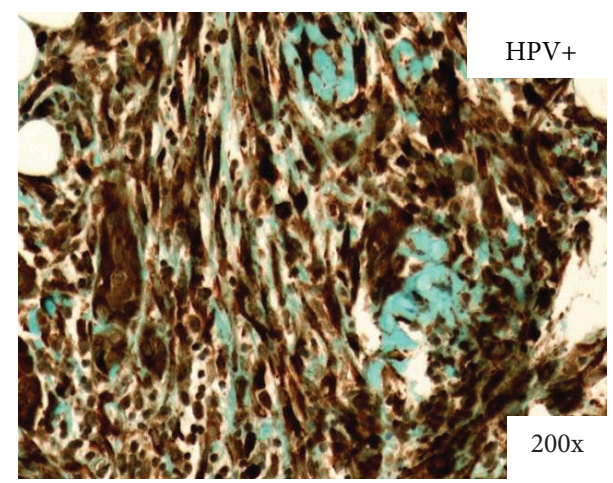

(d)

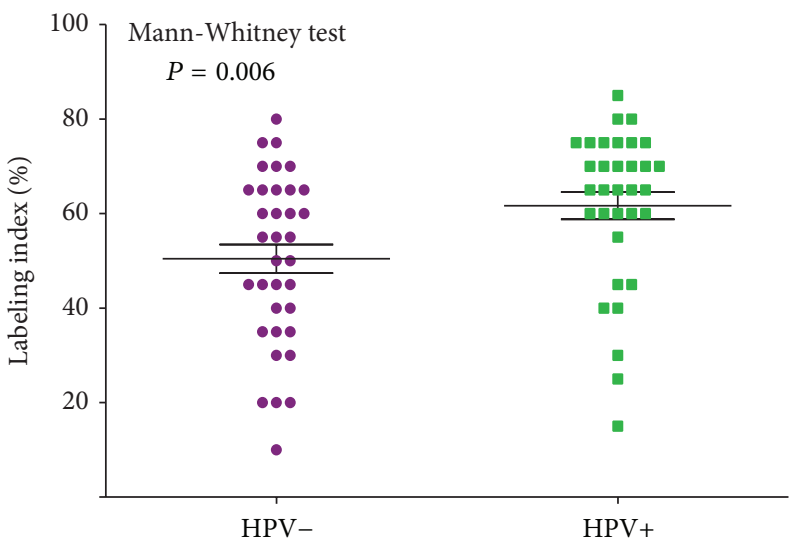

(e)

FIgURE 4: Typical immunohistochemical staining profile of PSCA in HPV- (c) and HPV+ (d) oral tumors. The graph represents the results of the Mann-Whitney test of the PSCA mean labeling index values in the $50 \mathrm{HPV}+$ and $50 \mathrm{HPV}-$ tumors (e). Panels (a) and (b) show positive and negative controls for PSCA in oral tumors, respectively.

Our second candidate protein, EEF1 $\alpha$, was overexpressed in the HPV- cell line. EEF1 $\alpha$ is a GTP-binding protein that interacts with aminoacyl-tRNA to recruit and deliver it to the A site of the ribosome during the elongation phase of protein translation. In addition to its role in protein translation, EEF1 $\alpha$ is involved in cell migration, cell morphology, protein synthesis, actin cytoskeleton organization, and the modulation of apoptosis sensitivity $[33,34]$. Due to its overexpression in many cancers, such as ovarian, breast, lung, and liver cancer, EEFl $\alpha$ has been defined as a putative oncogene [35]. This protein is of particular interest because a previous study reported that its downregulation in prostate cancer cells inhibits cell proliferation, invasion, and migration [36]. In contrast, increased EEF1 $\alpha$ expression is associated with increased cell proliferation, oncogenic transformation, and delayed cell senescence [37-39]. EEF1 also interacts with Akt to modulate its activity and regulate proliferation, survival, and motility in breast cancer cells [40]. Several authors reported that increased expression of this elongation factor is associated with tumorigenesis by enhancing the translation of genes promoting cell growth $[38,41]$.

To date, no clinical studies have demonstrated the involvement of PSCA or EEF1 $\alpha$ in head and neck carcinogenesis caused by viral infection, and their functions remain 


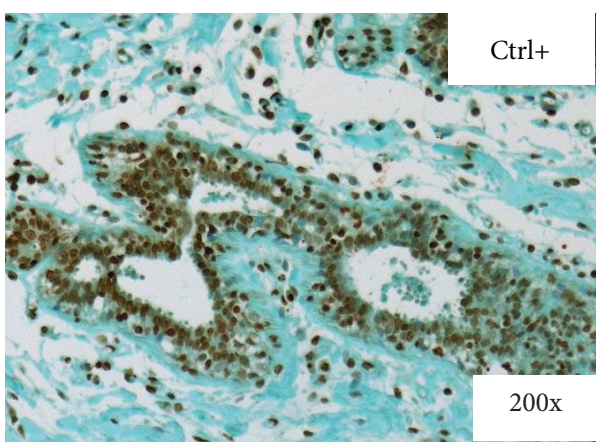

(a)

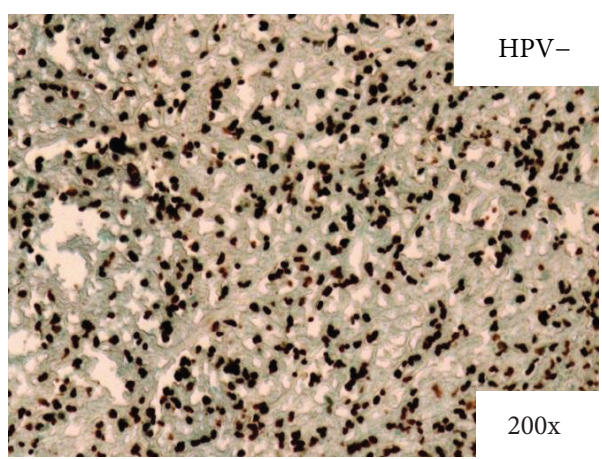

(c)

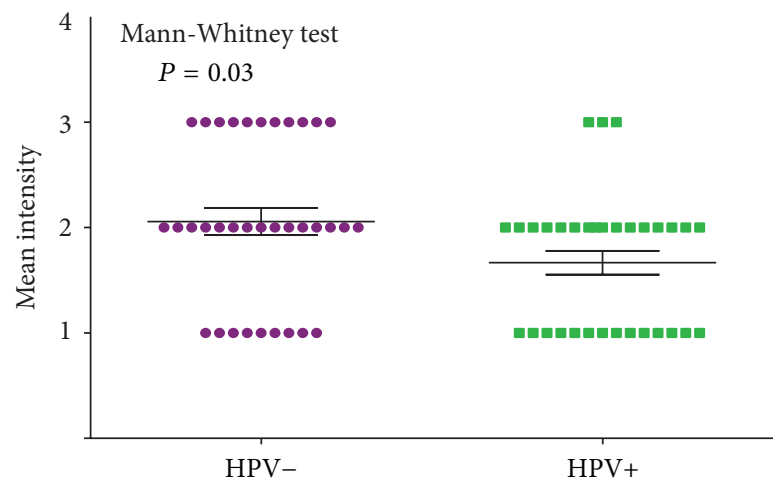

(e)

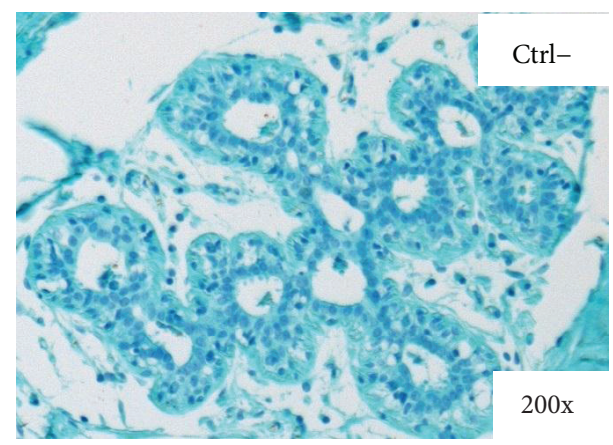

(b)

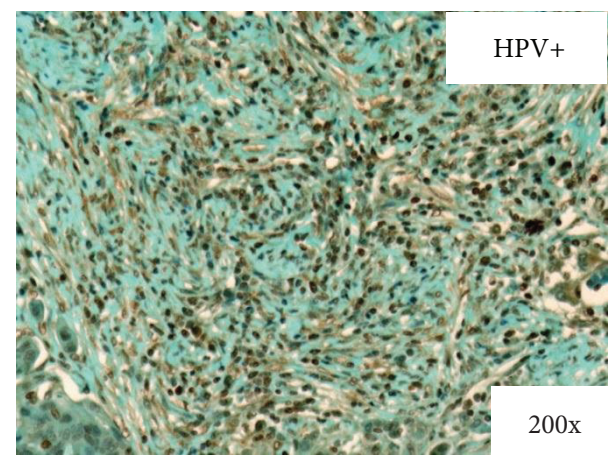

(d)

FIGURE 5: Typical immunohistochemical staining profile of EEF1 $\alpha$ in HPV- (c) and HPV+ (d) oral tumors. The graph represents the results of the Mann-Whitney test of the EEF1 $\alpha$ mean labeling index values in the $50 \mathrm{HPV}+$ and $50 \mathrm{HPV}-$ tumors (e). (a) and (b) show positive and negative controls for EEF1 $\alpha$ in oral tumors, respectively.

to be elucidated. This study will aid in our understanding of the mechanisms used by HPV to promote the development of head and neck cancers. In conclusion, PSCA and EEF1 meet several criteria, suggesting that they are involved in the biology of HPV-related HNSCC; however, further studies should be conducted to confirm our observations in a larger clinical series. Moreover, it will be interesting to perform functional experiments to understand the signaling pathways disrupted by HPV infection. By silencing several proteins, we plan to study the impact of gene extinction on cell proliferation, migration, invasion, and apoptosis to better understand the mechanisms used by HPV to drive carcinogenesis.

\section{Conflict of Interests}

The authors declare that there is no conflict of interests regarding the publication of this paper.

\section{Acknowledgments}

This work was partially financed by the FNRS under Grant "grand equipment" (no. 2877824). Géraldine Descamps is Ph.D. student who is supported by a Grant from the FNRS (Bourse Télévie). 


\section{References}

[1] O. Filleul, J. Preillon, E. Crompot, J. Lechien, and S. Saussez, "Incidence of head and neck cancers in Belgium: comparison with worldwide and French data," Bulletin du Cancer, vol. 98, no. 10, pp. 1173-1183, 2011.

[2] A. A. Ankola, R. V. Smith, R. D. Burk, M. B. Prystowsky, C. Sarta, and N. F. Schlecht, "Comorbidity, human papillomavirus infection and head and neck cancer survival in an ethnically diverse population," Oral Oncology, vol. 49, no. 9, pp. 911-917, 2013.

[3] C. C. R. Ragin and E. Taioli, "Survival of squamous cell carcinoma of the head and neck in relation to human papillomavirus infection: review and meta-analysis," International Journal of Cancer, vol. 121, no. 8, pp. 1813-1820, 2007.

[4] A. Duray, G. Descamps, C. Decaestecker et al., "Human papillomavirus DNA strongly correlates with a poorer prognosis in oral cavity carcinoma," Laryngoscope, vol. 122, no. 7, pp. 15581565, 2012.

[5] B. G. Hansson, K. Rosenquist, A. Antonsson et al., "Strong association between infection with human papillomavirus and oral and oropharyngeal squamous cell carcinoma: a populationbased case-control study in southern Sweden," Acta Oto-Laryngologica, vol. 125, no. 12, pp. 1337-1344, 2005.

[6] K. Rosenquist, J. Wennerberg, K. Annertz et al., "Recurrence in patients with oral and oropharyngeal squamous cell carcinoma: human papillomavirus and other risk factors," Acta Oto-Laryngologica, vol. 127, no. 9, pp. 980-987, 2007.

[7] K. Morshed, "Association between human papillomavirus infection and laryngeal squamous cell carcinoma," Journal of Medical Virology, vol. 82, no. 6, pp. 1017-1023, 2010.

[8] P. Ernoux-Neufcoeur, M. Arafa, C. Decaestecker et al., "Combined analysis of HPV DNA, p16, p21 and p53 to predict prognosis in patients with stage IV hypopharyngeal carcinoma," Journal of Cancer Research and Clinical Oncology, vol. 137, no. 1, pp. 173-181, 2011.

[9] A. Duray, G. Descamps, M. Arafa et al., "High incidence of highrisk HPV in benign and malignant lesions of the larynx," International Journal of Oncology, vol. 39, no. 1, pp. 51-59, 2011.

[10] M. L. Gillison, W. M. Koch, R. B. Capone et al., "Evidence for a causal association between human papillomavirus and a subset of head and neck cancers," Journal of the National Cancer Institute, vol. 92, no. 9, pp. 709-720, 2000.

[11] H. C. Hafkamp, J. J. Manni, A. Haesevoets et al., "Marked differences in survival rate between smokers and nonsmokers with HPV 16-associated tonsillar carcinomas," International Journal of Cancer, vol. 122, no. 12, pp. 2656-2664, 2008.

[12] W. Y. Lo, C. C. Lai, C. H. Hua et al., "S100A8 is identified as a biomarker of HPV18-infected oral squamous cell carcinomas by suppression subtraction hybridization, clinical proteomics analysis, and immunohistochemistry staining," Journal of Proteome Research, vol. 6, no. 6, pp. 2143-2151, 2007.

[13] H. W. Ott, H. Lindner, B. Sarg et al., "Calgranulins in cystic fluid and serum from patients with ovarian carcinomas," Cancer Research, vol. 63, no. 21, pp. 7507-7514, 2003.

[14] C. Melle, G. Ernst, R. Winkler et al., "Proteomic analysis of human papillomavirus-related oral squamous cell carcinoma: identification of thioredoxin and epidermal-fatty acid binding protein as upregulated protein markers in microdissected tumor tissue," Proteomics, vol. 9, no. 8, pp. 2193-2201, 2009.
[15] S. Marur and A. A. Forastiere, "Head and neck cancer: changing epidemiology, diagnosis, and treatment," Mayo Clinic Proceedings, vol. 83, no. 4, pp. 489-501, 2008.

[16] W. M. Koch, "Clinical features of HPV-related head and neck squamous cell carcinoma: presentation and work-up," Otolaryngologic Clinics of North America, vol. 45, no. 4, pp. 779-793, 2012.

[17] W. H. Westra, J. M. Taube, M. L. Poeta, S. Begum, D. Sidransky, and W. M. Koch, "Inverse relationship between human papillomavirus-16 infection and disruptive p53 gene mutations in squamous cell carcinoma of the head and neck," Clinical Cancer Research, vol. 15, no. 2, pp. 366-369, 2008.

[18] C. H. Chung and M. L. Gillison, "Human papillomavirus in head and neck cancer: its role in pathogenesis and clinical implications," Clinical Cancer Research, vol. 15, no. 22, pp. 6758-6762, 2009.

[19] J. Bernier, C. Domenge, M. Ozsahin et al., "Postoperative irradiation with or without concomitant chemotherapy for locally advanced head and neck cancer," The New England Journal of Medicine, vol. 350, no. 19, pp. 1945-1952, 2004.

[20] K. Lang, J. Menzin, C. C. Earle, J. Jacobson, and M. A. Hsu, “The economic cost of squamous cell cancer of the head and neck: findings from linked SEER-medicare data," Archives of Otolaryngology, Head \& Neck Surgery, vol. 130, no. 11, pp. 1269-1275, 2004.

[21] H. Ye, A. Wang, B. S. Lee et al., "Proteomic based identification of manganese superoxide dismutase 2 (SOD2) as a metastasis marker for oral squamous cell carcinoma," Cancer Genomics and Proteomics, vol. 5, no. 2, pp. 85-94, 2008.

[22] R. E. Reiter, Z. Gu, T. Watabe et al., "Prostate stem cell antigen: a cell surface marker overexpressed in prostate cancer," Proceedings of the National Academy of Sciences of the United States of America, vol. 95, no. 4, pp. 1735-1740, 1998.

[23] G. Bahrenberg, A. Brauers, H. G. Joost, and G. Jakse, "Reduced expression of PSCA, a member of the LY- 6 family of cell surface antigens, in bladder, esophagus, and stomach tumors," Biochemical and Biophysical Research Communications, vol. 275, no. 3, pp. 783-788, 2000.

[24] Z. Gu, G. Thomas, J. Yamashiro et al., "Prostate stem cell antigen (PSCA) expression increases with high gleason score, advanced stage and bone metastasis in prostate cancer," Oncogene, vol. 19, no. 10, pp. 1288-1296, 2000.

[25] A. G. de Nooij-van Dalen, G. A. van Dongen, S. J. Smeets et al., "Characterization of the human Ly-6 antigens, the newly annotated member Ly-6K included, as molecular markers for headand-neck squamous cell carcinoma," International Journal of Cancer, vol. 103, no. 6, pp. 768-774, 2003.

[26] T. Kawaguchi, M. Sho, T. Tojo et al., "Clinical significance of prostate stem cell antigen expression in non-small cell lung cancer," Japanese Journal of Clinical Oncology, vol. 40, no. 4, pp. 319-326, 2010.

[27] N. Saeki, J. Gu, T. Yoshida, and X. Wu, "Prostate stem cell antigen: a Jekyll and Hyde molecule?" Clinical Cancer Research, vol. 16, no. 14, pp. 3533-3538, 2010.

[28] D. F. Stroncek, L. Caruccio, and M. Bettinotti, "CD177: a member of the Ly- 6 gene superfamily involved with neutrophil proliferation and polycythemia vera," Journal of Translational Medicine, vol. 2, no. 1, article 8, 2004.

[29] A. Hänninen, I. Jaakkola, M. Salmi, O. Simell, and S. Jalkanen, "Ly-6C regulates endothelial adhesion and homing of $\mathrm{CD}^{+} \mathrm{T}$ cells by activating integrin-dependent adhesion pathways," 
Proceedings of the National Academy of Sciences of the United States of America, vol. 94, no. 13, pp. 6898-6903, 1997.

[30] S. K. Lee, B. Su, S. E. Maher, and A. L. M. Bothwell, "Ly-6A is required for $\mathrm{T}$ cell receptor expression and protein tyrosine kinase fyn activity," The EMBO Journal, vol. 13, no. 9, pp. 21672176, 1994.

[31] Z. Zhao, W. Ma, G. Zeng, D. Qi, L. Ou, and Y. Liang, "Small interference RNA-mediated silencing of prostate stem cell antigen attenuates growth, reduces migration and invasion of human prostate cancer PC-3M cells," Urologic Oncology, vol. 31, no. 3, pp. 343-351, 2013.

[32] H. Ono, N. Hiraoka, Y. S. Lee et al., "Prostate stem cell antigen, a presumable organ-dependent tumor suppressor gene, is downregulated in gallbladder carcinogenesis," Genes Chromosomes and Cancer, vol. 51, no. 1, pp. 30-41, 2012.

[33] S. R. Gross and T. G. Kinzy, "Translation elongation factor 1A is essential for regulation of the actin cytoskeleton and cell morphology," Nature Structural and Molecular Biology, vol. 12, no. 9, pp. 772-778, 2005.

[34] A. Duttaroy, D. Bourbeau, X. L. Wang, and E. Wang, "Apoptosis rate can be accelerated or decelerated by overexpression or reduction of the level of elongation factor-1 $\alpha$," Experimental Cell Research, vol. 238, no. 1, pp. 168-176, 1998.

[35] G. van Goietsenoven, J. Hutton, J. P. Becker et al., "Targeting of eEF1A with Amaryllidaceae isocarbostyrils as a strategy to combat melanomas," The FASEB Journal, vol. 24, no. 11, pp. 45754584, 2010.

[36] G. Zhu, W. Yan, H. C. He et al., "Inhibition of proliferation, invasion, and migration of prostate cancer cells by downregulating elongation factor- $1 \alpha$ expression," Molecular Medicine, vol. 15, no. 11-12, pp. 363-370, 2009.

[37] B. T. Edmonds, J. Wyckoff, Y.-G. Yeung et al., "Elongation factor- $1 \alpha$ is an overexpressed actin binding protein in metastatic rat mammary adenocarcinoma," Journal of Cell Science, vol. 109, no. 11, pp. 2705-2714, 1996.

[38] N. Anand, S. Murthy, G. Amann et al., "Protein elongation factor EEF1A2 is a putative oncogene in ovarian cancer," Nature Genetics, vol. 31, no. 3, pp. 301-305, 2002.

[39] B. T. Edmonds, J. Murray, and J. Condeelis, "pH regulation of the F-actin binding properties of Dictyostelium elongation factor $1 \alpha$," The Journal of Biological Chemistry, vol. 270, no. 25, pp. 15222-15230, 1995.

[40] L. Pecorari, O. Marin, C. Silvestri et al., "Elongation factor 1 alpha interacts with phospho-Akt in breast cancer cells and regulates their proliferation, survival and motility," Molecular Cancer, vol. 8, no. 1, article 58, 2009.

[41] N. Sonenberg, "Translation factors as effectors of cell growth and tumorigenesis," Current Opinion in Cell Biology, vol. 5, no. 6, pp. 955-960, 1993. 


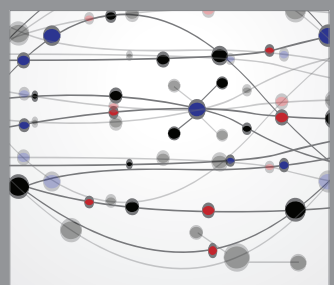

The Scientific World Journal
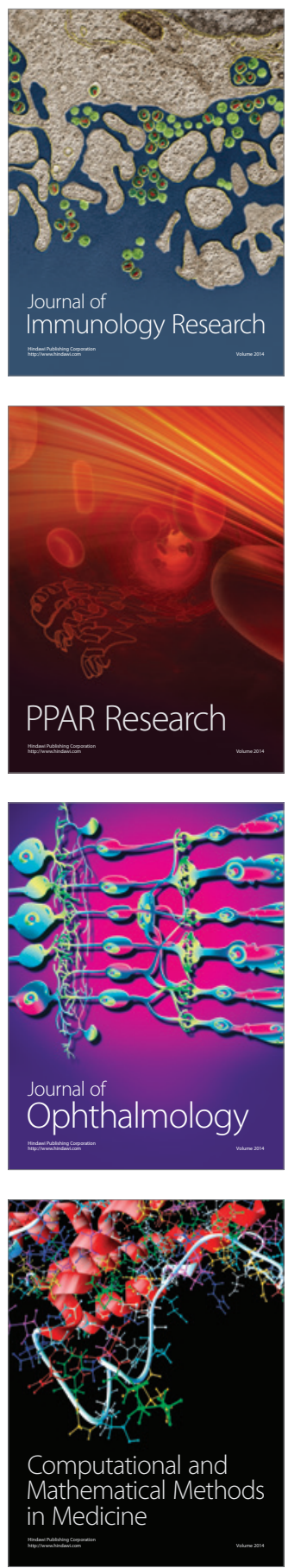

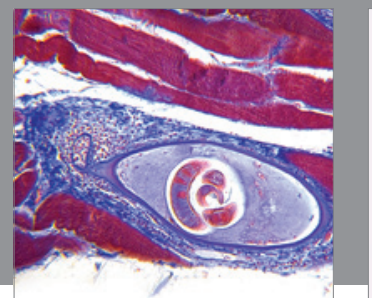

Gastroenterology

Research and Practice
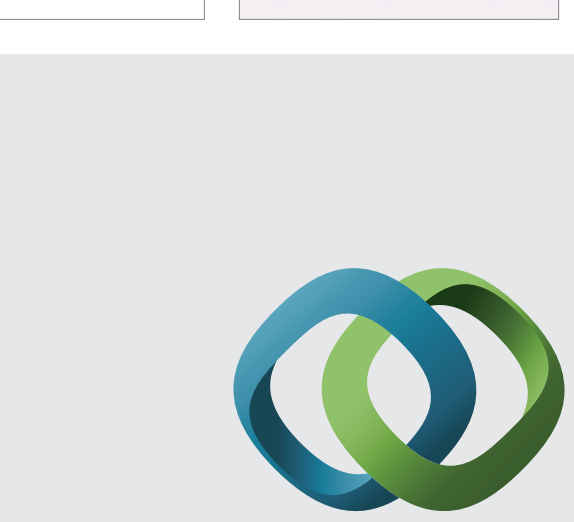

\section{Hindawi}

Submit your manuscripts at

http://www.hindawi.com
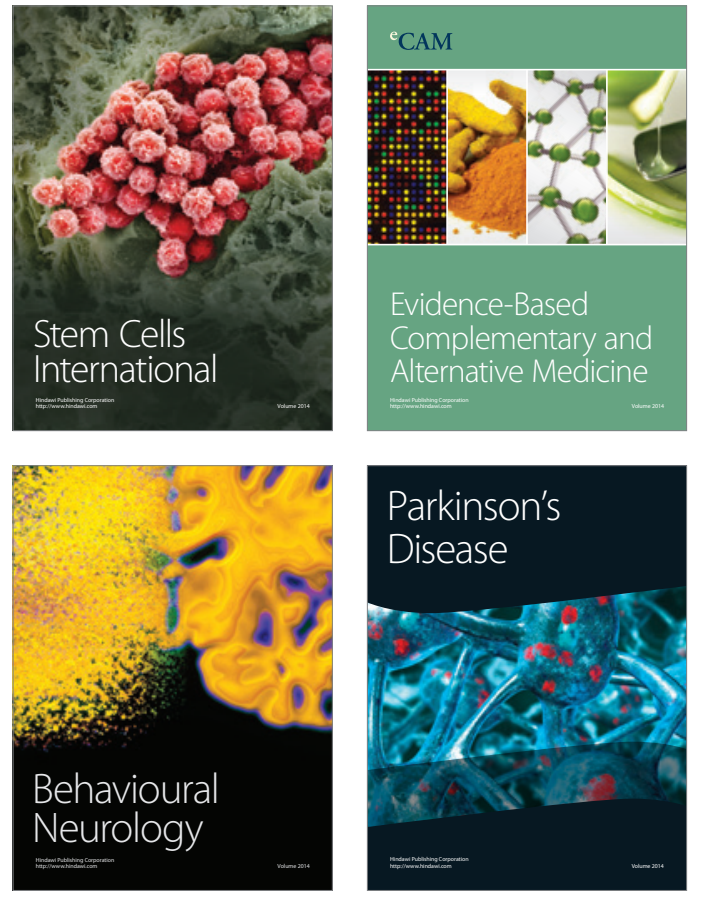
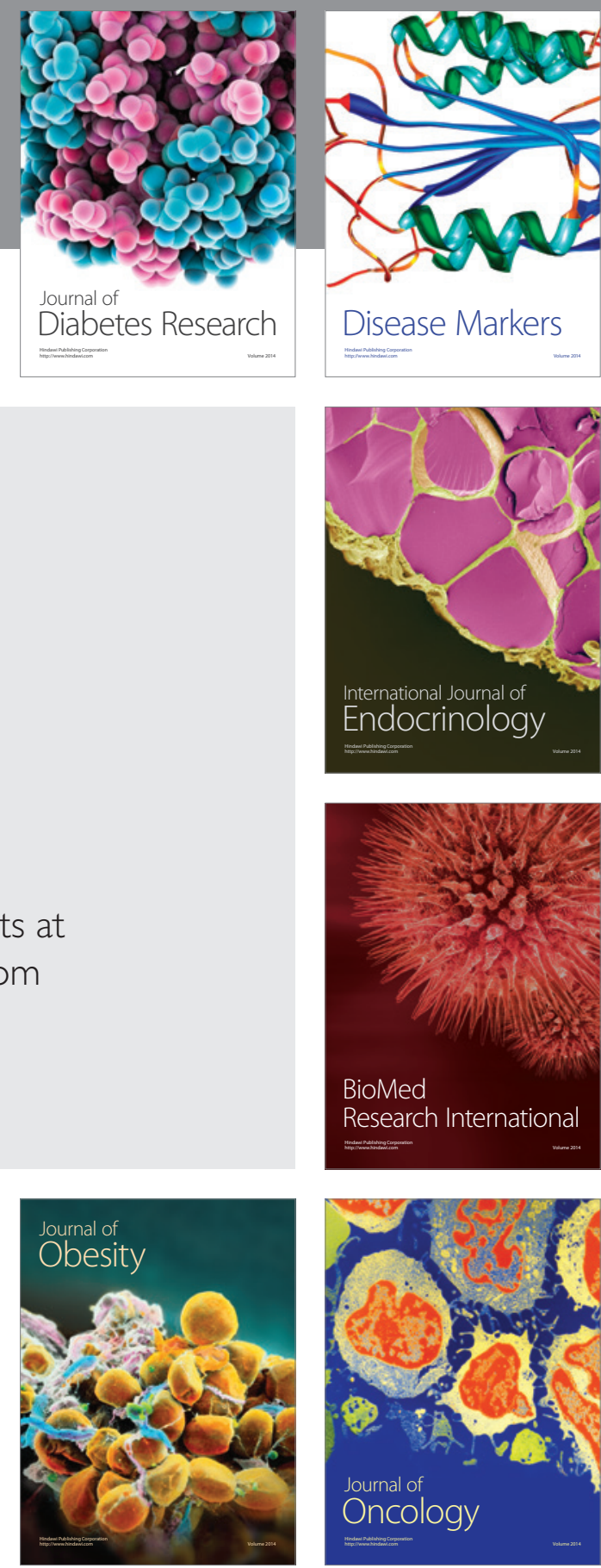

Disease Markers
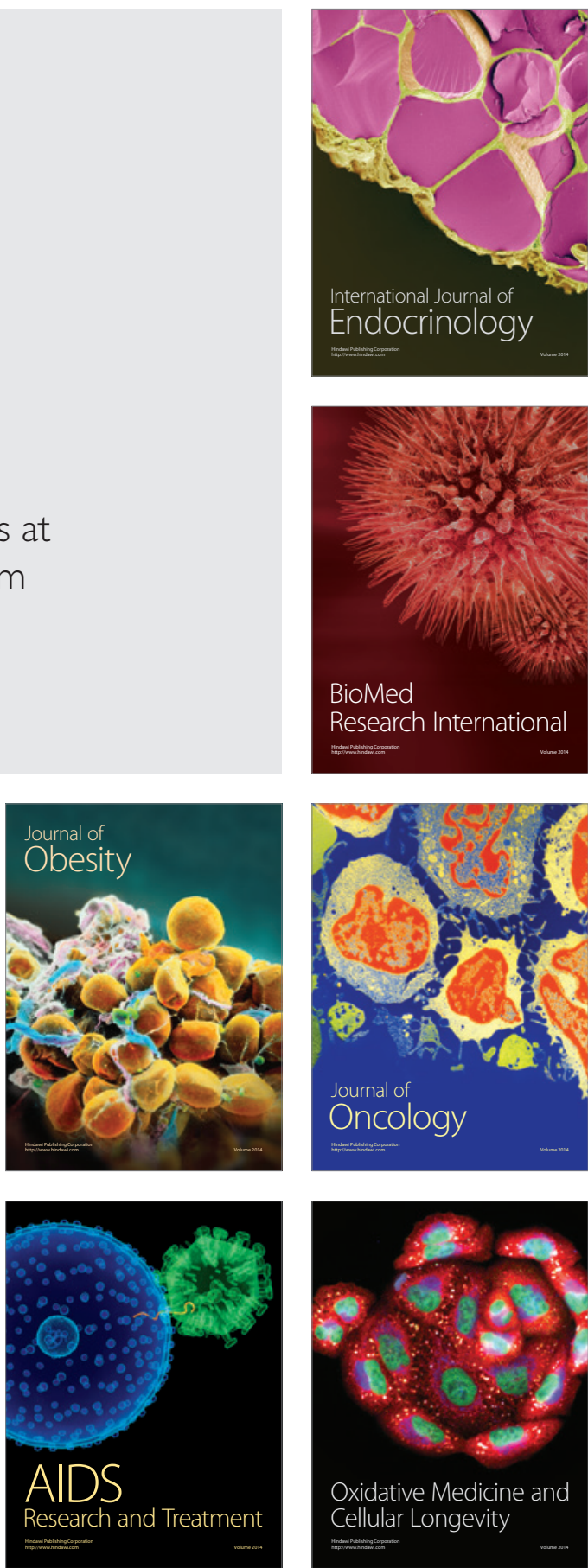